\title{
Is the faint young Sun problem for Earth solved?
}

\author{
Benjamin Charnay - Eric T. Wolf - Bernard Marty • François Forget
}

Received: date / Accepted: date

\begin{abstract}
Stellar evolution models predict that the solar luminosity was lower in the past, typically 20-25 $\%$ lower during the Archean (3.8-2.5 Ga). Despite the fainter Sun, there is strong evidence for the presence of liquid water on Earth's surface at that time. This "faint young Sun problem" is a fundamental question in paleoclimatology, with important implications for the habitability of the early Earth, early Mars and exoplanets. Many solutions have been proposed based on the effects of greenhouse gases, atmospheric pressure, clouds, land distribution and Earth's rotation rate. Here we review the faint young Sun problem for Earth, highlighting the latest geological and geochemical constraints on the early Earth's atmosphere, and recent results from 3D global climate models and carbon cycle models. Based on these works, we argue that the faint young Sun problem for Earth has essentially been solved. Unfrozen Archean oceans were likely maintained by higher concentrations of $\mathrm{CO}_{2}$, consistent with the latest geological
\end{abstract}

\section{B. Charnay}

LESIA, Observatoire de Paris, Université PSL, CNRS, Sorbonne Université, Université de Paris, 5 place Jules Janssen, 92195 Meudon, France.

E-mail: benjamin.charnay@obspm.fr

\section{E. T. Wolf}

University of Colorado, Boulder, Laboratory for Atmospheric and Space Physics, Department of Atmospheric and Oceanic Sciences, Boulder, CO 80302, USA.

B. Marty

Centre de Recherches Pétrographiques et Géochimiques, UMR 7358 CNRS - Université de Lorraine, 15 rue Notre Dame des Pauvres, BP 20, 54501 Vandoeuvre-lès-Nancy, France.

\section{F. Forget}

Laboratoire de Météorologie Dynamique/IPSL, CNRS, Sorbonne Université, Ecole Normale Supérieure, PSL Research University, Ecole Polytechnique, 75005 Paris, France. proxies, potentially helped by additional warming processes. This reinforces the expected key role of the carbon cycle for maintaining the habitability of terrestrial planets. Additional constraints on the Archean atmosphere and 3D fully coupled atmosphere-ocean models are required to validate this conclusion.

Keywords Early Earth · Paleoclimates · Habitability

\section{Introduction}

Let's imagine time-travelers exploring the early Earth 3-4 billions years ago. Leaving their time capsule, they would need oxygen masks to survive in the anoxic Archean atmosphere, containing deathly high levels of carbon dioxide and possibly also methane, carbon monoxide, ammonia and hydrocyanic acid. Moreover, with no appropriate protection, they would quickly suffer from sunburn, due to the higher UV flux of the early Sun and the absence of an ozone layer. Passed these complications, they would then discover a world very different from our present-day Earth. The sky would look hazier, potentially with an orange colour. The days would be shorter and a larger moon would shine in the nightsky. The Sun would appear significantly fainter than today. However, perhaps surprisingly, most of the surface would be covered by temperate or warm liquid water oceans. These oceans would be more acidic and full of unicellular organisms forming a productive biosphere. Our time-travelers may wonder how can the climatic conditions be clement under such a fainter Sun. Theywould experience the faint young Sun problem, one of the most fundamental questions in paleoclimatology.

The faint young Sun problem for Earth has been reviewed in detail by Feulner 2012. At that time, most of the atmospheric modelling work was based on 1D 
radiative convective models ( $\mathrm{RCMs}$ ). While $1 \mathrm{D} \mathrm{RCMs}$ remain attractive research tools due to their flexibility and computational efficiency, 1D models miss important climate feedbacks. For instance, RCMs used in early Earth and habitability studies typically omit explicit representations of clouds and surface ice and snow. Instead, the surface albedo is assigned a constant high value, to implicitly represent cloud reflectivity. By treating the radiative effect of clouds in this manner, such models fail to include the longwave radiative effect of clouds and can overestimate the greenhouse effect of background gases Pierrehumbert, 1995, Goldblatt and Zahnle, 2011a. They also miss cloud feedbacks related to changes in the cloud distribution.

Three-dimensional atmospheric general circulation models (GCMs) coupled to simple ocean/sea-ice models represent a significant improvement in the simulation of the climate system compared to $1 \mathrm{D}$ RCMs. GCMs allow for a self-consistent and coupled treatment of numerous dynamical and physical processes occurring in planetary atmospheres. Of particular importance for Earth's climate system, is the treatment of water in its various thermodynamic phases. In particular, water is responsible for the sea-ice albedo, water vapor greenhouse and cloud feedbacks, which can all strongly impact the climate sensitivity. Shortly after the review from Feulner 2012, several papers using 3D atmospheric GCMs coupled to simple ocean/sea-ice models were published, providing a fresh new perspective and some answers about former proposed solutions to the faint young Sun problem Charnay et al. 2013 , Wolf and Toon, 2013, 2014, Le Hir et al., 2014, Kunze et al., 2014, Teitler et al., 2014, Charnay et al., 2017; Wolf et al. 2018. According to these modelling studies, the faint young Sun problem appears less severe than initially thought, notably because of cloud feedbacks leading to optically thinner low clouds on the early Earth.

In parallel, new geological and geochemical constraints were obtained during the last decade, changing the general view about the evolution of Earth's atmospheric nitrogen, as well as constraints on atmospheric $\mathrm{CO}_{2}$ and surface temperatures during the Archean. In particular, some of these recent studies suggest relatively high $\mathrm{pCO}_{2}$ values, which mitigate the faint young Sun problem.

This paper constitutes a general review of the faint young Sun problem for Earth, highlighting atmospheric modelling results and some laboratory measurements obtained during the last decade. In section 2, we describe the environment of the early Earth, in particular the evidence for a weaker Sun, for the presence of surface liquid water, and for the fraction of emerged land. We also detail constraints on the ocean temperature and atmospheric composition/pressure. Section 3 lists different proposed solutions to the faint young Sun problem, including the effects of greenhouse gases, atmospheric pressure, clouds and the fraction of emerged land. For each solution, we highlight recent results from climate modelling and paleosol studies. Section 4 reviews the lessons from $3 \mathrm{D}$ global climate models and the differences compared to 1D atmospheric models. Section 5 discusses the role of the carbon-cycle and life to regulate the early Earth's climate. Finally, we conclude in section 6 with a summary and possible directions for future research.

\section{The environment of the early Earth}

\subsection{Evidence for a weaker Sun}

It has been well established in models of solar evolution that solar luminosity has slowly increased over the lifetime of the Sun. 3.8 billions years ago the early solar flux is calculated to have been $25 \%$ lower than today and it has slowly intensified since (see e.g. Newman and Rood 1977; Gough 1981). This is because the fusion of hydrogen into helium increases the mean molecular weight of the core. To maintain the balance between the pressure gradient force and gravity, the core contracts and warms. The increased densities and temperatures enhance the rate of fusion and hence, the star's luminosity increases with time. This model is very robust. Furthermore, it is based on a model of the Sun which agrees very well with solar neutrinos measurements and helioseismology observations.

Can this model be questioned? Is it possible to imagine a young Sun brighter than expected that could resolve the faint young Sun problem and possibly explain the very warm temperature that have been reported by some studies? More than for the Earth, such a possibility has been discussed to resolve the enigma of early Mars covered by rivers and lakes 3.5 - 4 billions years ago Whitmire et al., 1995, Forget et al., 2013, Haberle et al. 2017.

The only way to explain a brighter early Sun while remaining consistent with the robust theory mentioned above is to assume that it was more massive initially and that it subsequently lost the excess mass in a solar wind much more intense than today Whitmire et al. 1995. Solar luminosity is proportional to the fourth power of solar mass $M_{\odot}$, and since a planet's orbital distance $r$ is inversely proportional to $M_{\odot}$, and the solar flux varies as $r^{-2}$, the flux at a planet scales as $F \sim M_{\odot}^{6}$ Whitmire et al. 1995]. Therefore a few percent of the 
mass would be sufficient. An initial mass of $\sim 6 \%$ higher than today makes the Sun as bright as today 4.5 Ga.

For years, this assumption has been regarded with skepticism by the community, because of the lack of evidence and the success of the "Standard Solar Model" of the Sun. However, a decade ago some inconsistencies between the standard solar model predictions and measurements of the solar CNO abundances were revealed Asplund et al. 2009; Caffau et al. 2008, 2010. Interestingly a younger more massive Sun was then suggested to explain these inconsistencies Guzik and Mussack, 2010, Turck-Chièze et al., 2011. Overall assuming an early massive Sun has consequences on the modelled solar evolution and leaves traces on the numerous observational constraints that are available for the Sun itself (seismic properties, neutrino fluxes, composition). Yet the most recent studies on the subject conclude that these datasets cannot rule out the early massive Sun hypothesis (See Wood et al. 2018; Buldgen et al. [2019], and references therein).

The intensity and the evolution of the early solar wind remain open questions. Unfortunately, the basic mechanisms responsible for producing winds from solarlike main sequence stars are still not understood well enough to provide quantitative information. Ideally, much could be learned by observing stellar winds around other stars at various ages. However stellar winds from solarmass stars are very difficult to observe directly owing to their low optical depth. Some studies have been performed by looking for the Ly $\alpha$ signature of the charge exchange that occurs when the ionized stellar wind collides with the neutral interstellar medium Zank, 1999. Wood et al., 2002, 2005. Analysing these observations for stars of various ages suggest that stellar winds may decrease exponentially with time and that most of the extra mass was lost in less than a few hundreds of million years Wood et al., 2005, Minton and Malhotra, 2007. Observations of the radio emission of young solar-type stars suggest a total solar mass loss lower than $2 \%$ after 100 Myr Fichtinger et al., 2017]. Finally, observations of stellar spin down rate have been used to argue in favour of a large and sustained mass loss and a more massive young Sun [Martens, 2017, but they also suggest an exponential decrease of the mass loss Gallet and Bouvier, 2013.

Therefore the key difficulty in solving the faint young Sun problem with a more massive sun is to keep the Sun sufficiently massive and bright for one or two billion of years, throughout the Archean. Observations of young solar analogs tend to rule out this possibility, although more data are required to be certain Wood et al. 2018. In the future, it may be possible to constrain the Sun's ancient mass and its evolution by looking for remaining signatures of the early solar wind and the effects of a solar mass-loss history on the orbital dynamics in the planetary system, including possible signatures in the geological and climate record Minton and Malhotra, 2007; Spalding et al., 2018.

\subsection{Evidence for liquid water}

The oceans might have formed rapidly in a gigantic deluge, a few Myr after the cataclysm that led to the Earth-Moon system, 4.5 Gyr ago Sleep et al., 2001. Some models predict that oceans could have formed even earlier and could have partly survived the Moon forming event Genda and Abe, 2005]. The first evidence for the presence of liquid water on Earth derives from the analysis of fragments of Archean zircons. Zircons are U-rich magmatic minerals that are resilient enough to have survived several mountain building cycles. Some of them contain fragments having $\mathrm{U}-\mathrm{Pb}$ ages up to 4.24.4 Ga Wilde et al. 2001; Mojzsis et al. 2001. These old zircons present oxygen isotopic compositions that cannot be explained by a dry magmatic genesis and require contribution of material having been hydrothermally altered at low temperature. Direct geologic evidence of oceans stems from the occurrence of pillow basalts and layered banded iron formations in $3.8 \mathrm{Ga}$ units, demonstrating underwater magmatism and sedimentation at, or prior to, that time. Well preserved formations with low metamorphic grades abound 3.5 Ga ago in NW Australia and South Africa. Hydrothermal quartz at that ages contain fluid inclusions which contain mixtures of hydrothermal end-member(s) and Archean seawater Foriel et al., 2004. Coupled Cl-KAr study suggests a salinity comparable to the modern one and, possibly temperatures in the range $20-40^{\circ} \mathrm{C}$ (see below) Marty et al. 2018. Both thermal modelling and field evidence are consistent with the occurrence of liquid water on Earth within a few tens of Ma after the formation of the solar system, with direct evidence for oceans at 3.8-3.5 Ga.

\subsection{Constraints on the fraction of land}

The fraction of emerged land affects the surface albedo and thus the planetary energy budget. The emergence of land required the development of continents able to float over the denser mantle. Hence the continental lithosphere needed to be strong enough to support crustal thickening and high reliefs Rey and Coltice, 2008. The period of time when this happened is difficult to estimate and models are generally based on the distribution of old continental crust terrains, as well 
as on the petrology and geochemistry of these geological units Allegre and Rousseau, 1984, Belousova et al., 2010, Dhuime et al. [2012; Pujol et al. [2013]. These models propose major pulses of crustal generation in the period $4 \mathrm{Ga}-3 \mathrm{Ga}$ that resulted in $60-80 \%$ presentday volume at $3 \mathrm{Ga}$ (see Figs. 5 \& 6 in Hawkesworth et al. 2019]). After $3 \mathrm{Ga}$, the net growth rate diminished because crustal destruction became effective and competed efficiently with crustal generation. This period of time may mark the onset of modern-style plate tectonics. A lower continental crust volume combined with potentially a larger ocean volume Pope et al. 2012 logically implies less emerged land during the Archean than today. Flament et al. 2008 estimated that the fraction of emerged land was lower than $12 \%$ and probably around $2-3 \%$ (compared to $27 \%$ today).

\subsection{Geological constraints on the temperature}

A long debate is still ongoing about the temperature of the early oceans. Archean oceanic cherts $\left(\mathrm{SiO}_{2}\right)$ appear depleted in ${ }^{18} \mathrm{O}$ relative to ${ }^{16} \mathrm{O}$ Knauth and Lowe, 2003; Robert and Chaussidon, 2006, Tartese et al., 2016]. A possible explanation of this trend is related to the temperature of Archean oceans. Indeed, cherts concentrate less ${ }^{18} \mathrm{O}$ relative to seawater during their formation as oceanic temperature increases. The low $\delta^{18} \mathrm{O}$ have thus been interpreted to suggest hot oceans with temperatures between $60^{\circ} \mathrm{C}(333 \mathrm{~K})$ and $80^{\circ} \mathrm{C}(353 \mathrm{~K})$ Knauth and Lowe, 2003, Robert and Chaussidon, 2006, Tartese et al. | 2016. . Notably, silicon isotopes coupled with oxygen isotopes also attest for oceanic temperatures warmer than today Robert and Chaussidon, 2006. The temperature range inferred from Archean cherts is compatible with the thermophiles inferred from evolutionary models of the ancient life Gaucher et al. 2008, with constraints on the salinity of Archean oceans [Marty et al. 2018, and possibly with the indications for a low ocean water viscosity Fralick and Carter, 2011]. If the interpretation of low $\delta^{18} \mathrm{O}$ in Archean cherts is correct, such high oceanic temperatures would make the faint young Sun problem for Earth much more difficult to overcome (see section 4.2 and 5 ).

However, the interpretation of $\delta^{18} \mathrm{O}$ isotope ratio as indicator of warm Archean oceans has been strongly debated. Some analyses suggest temperate oceans with temperatures lower than $40^{\circ} \mathrm{C}$ [Hren et al., 2009; Blake et al. 2010. In addition, most of Archean cherts did not directly precipitate from seawater or may not be sufficiently well preserved to be used to reconstruct past oceanic temperature Marin-Carbonne et al., 2012, 2014, Cammack et al., 2018. Other possible explanations have been proposed as hydrothermal alteration of the seafloor van den Boorn et al., 2007 or as a gradual changes in the oxygen isotope composition of seawater Kasting and Howard, 2006, Jaffrés et al., 2007]. That latter criticism has been ruled out by Tartese et al. [2016], who investigated $\mathrm{O}$ isotopes not in cherts but in kerogen and demonstrated that the ocean $\delta^{18} \mathrm{O}$ composition remained almost constant. The triple oxygen isotope mass balance model from Sengupta and Pack 2018 suggests that Archean cherts precipitated in cool oceans with modern-like $\delta^{18} \mathrm{O}$ followed by diagenetic alteration.

In addition, warm/hot Archean oceans are difficult to reconcile with the glacial evidence. The glacial Archean record includes the Huronian glaciations at $2.4 \mathrm{Ga}$ and glacial rocks at $3.5,2.9 \mathrm{Ga}$ and $2.7 \mathrm{Ga}$ Kasting and Howard, 2006, Ojakangas et al., 2014, de Wit and Furnes 2016]. The Huronian glaciations were likely Snowball Earth events, where the entire planet was encases in ice, while the others were likely only partial glaciations. They imply global mean temperatures below $20^{\circ} \mathrm{C} d e$ Wit and Furnes, 2016, at least episodically. The transitions from warm climates with mean surface temperature around $60^{\circ} \mathrm{C}$ to cold climates or Snowball-Earth events would imply major changes in the atmospheric composition and in the carbon cycle, implying unknown mechanisms. Such swings in the carbon cycle seem unlikely, although the glacial events may represent only a small fraction of the Archean period.

Finally, evolutionary models suggest thermophilic ancient life but also a mesophilic last universal common ancestor (LUCA) Bousseau et al. 2008. These molecular thermometers do not give information about the global mean surface temperature. Thermophily near the roots of the tree of life may reflect local warm environments (like hydrothermal vents) or survival after hot climates produced by large impacts Bousseau et al. 2008, Abramov and Mojzsis, 2009.

We conclude that the debate about the temperature of the early oceans is not over, although the arguments for cold or temperate climates seem stronger now. We discuss later the implications of both cases in the context of the faint young Sun problem.

2.5 Geological constraints on the atmospheric composition and pressure

The atmospheric composition and pressure in the distant past are primarily estimated from models of the origin(s) of atmospheric volatiles and from models of atmospheric evolution upon interactions with outer space and exchanges with the solid Earth (see the review by Catling and Zahnle 2020 and references therein). Noble gas isotope systematics indicate that the atmosphere is an ancient reservoir that was formed a few 
tens of Ma after start of solar system formation 4.56 Ga ago, by degassing of material that accreted to form our planet. The geological record of ancient sediments and their weathering profile is consistent with relatively low partial pressures of $\mathrm{CO}_{2}\left(\mathrm{pCO}_{2}<30\right.$ mbar $)$ for the late Archean Sheldon, 2006, Driese et al., 2011]. A recent technique involving the modelling of the aqueous chemistry in paleosols gives higher estimations for $\mathrm{pCO}_{2}$ during the Archean $\left(\mathrm{pCO}_{2}=24-140\right.$ mbar at 2.77 Ga, 22-700 mbar at $2.75 \mathrm{Ga}$ and $45-140$ mbar at 2.46 $\mathrm{Ga}$ ) and a gradual decrease with time Kanzaki and Murakami, 2015]. Rosing et al. 2010 derived a very low upper limit of $\sim 0.9$ mbar from the coexistence of siderite and magnetite in Archean banded iron formation. That limit based on thermodynamic arguments has yet been questioned Reinhard and Planavsky, 2011. Finally, Lehmer et al. 2020] interpreted the oxidation state of micrometeorites at $2.7 \mathrm{Ga}$ as a possible evidence for a $\mathrm{CO}_{2}$ atmospheric mixing ratio $>70 \%$. These geological constraints on $\mathrm{pCO}_{2}$ are generally still debated, do not cover all times of the Archean, and are often incompatible. Therefore, we do not think that they should be considered as strict limits. The geological record also suggests the onset of an oxygenated atmosphere around $2.4 \mathrm{Ga}$, called the Great Oxidation Event Lyons et al. 2014. Removing $\mathrm{CO}_{2}$ and $\mathrm{O}_{2}$ from the atmospheric composition leaves $\mathrm{N}_{2}$, water vapour, noble gases and several $\mathrm{C}$ species as the main atmospheric constituents.

Geological measurements of the atmospheric pressure and compositions in the distant past were thought to be impossible due to the mobility of volatile elements in rocks and minerals undergoing metamorphism. Surprisingly, this assumption was not correct and new types and samples and new approaches permit measurable constraints to be determined. Marty et al. 2013] analyzed volatiles trapped in fluid inclusions in $3.5 \mathrm{Ga}$ hydrothermal quartz from the Pilbara, NW Australia. ${ }^{36} \mathrm{Ar}$ is a primordial isotope that has been conserved in the atmosphere, as indicated by constant ${ }^{38} \mathrm{Ar} /{ }^{36} \mathrm{Ar}$ ratio. ${ }^{40} \mathrm{Ar}$ is a radiogenic isotope produced by the decay of crustal and mantle ${ }^{40} \mathrm{~K}$. The triple bond of $\mathrm{N}_{2}$ makes this molecule very stable and $\mathrm{N}_{2}$ is sometimes referred as "the sixth noble gas". In a ${ }^{40} \mathrm{Ar} /{ }^{36} \mathrm{Ar}$ versus $\mathrm{N}_{2} /{ }^{36} \mathrm{Ar}$ frame, these authors found that data from vacuum crushing experiments define a straight line representing mixing between a low ${ }^{40} \mathrm{Ar} /{ }^{36} \mathrm{Ar}, \mathrm{N}_{2} /{ }^{36} \mathrm{Ar}$ endmember representing paleo-atmospheric noble gases dissolved in seawater and an hydrothermal component rich in crustal ${ }^{40} \mathrm{Ar}$ and $\mathrm{N}$. The extrapolated seawater $\mathrm{N}_{2} /{ }^{36} \mathrm{Ar}$ ratio was comparable to, or lower than, the modern value, leading Marty et al. 2013] to propose that the $\mathrm{pN}_{2}$ was $\leq 1.1$ bar and possibly as low as 0.5 bar. The authors also found that the $\mathrm{N}$ isotopic composition of
Archean air was similar to the modern composition, thus discarding the possibility of isotopically fractionating atmospheric escape of nitrogen since $3 \mathrm{Ga}$. Avice et al. 2018 developed a similar study for several samples from another area (Berberton, South Africa) and proposed that the Archean $\mathrm{pN}_{2}$ was $\leq 0.5$ bar. Independently, Som et al. [2012] attempted to set constraints on the barometric pressure in the distant past from fossil imprints of raindrops. The rationale is that the maximum size of raindrops is a function of the $\mathrm{P}_{a t m}$ as raindrop will fragment over a threshold size due to air drag. These authors measured $2.7 \mathrm{Ga}$ imprints of raindrops and conducted in parallel analogic experiments to conclude that the Archean atmospheric pressure could not have been higher than 2.3 bar and was probably below 1.3 bar. This upper limit has been criticised by Kavanagh and Goldblatt 2015, because the analysis of fossil imprints can be biased by very rare large raindrops. Goosmann et al. 2018 argued that such a bias is statistically unlikely given that 18 distinct bedding surfaces were analysed by Som et al. 2012].

In a further study, Som et al. [2016] proposed an absolute barometric pressure of $0.23 \pm 0.23$ bar using the size distribution of gas bubbles in 2.5 Ga basaltic lava flows that solidified at sea level. The maximum size that bubbles can reach in a lava flow is a function of the external pressure on the surface of the flow, here the barometric pressure. They compared the bubble sizes for two different layers in the flow, at a given depth (which pressure can be evaluated from the weight of the lava column above) and at the flow's surface, determined from morphological arguments. Som et al. 2016 suggested 0.5 bar as an upper limit for $\mathrm{P}_{a t m}$. Together, these studies suggest a surprisingly low barometric pressure for the Archean atmosphere, with little room for $\mathrm{pCO}_{2}$, which given errors could not have been above 0.5 bar, and possibly in the range 0-0.2 bar. However, little is known about this long period of time for which sample ages cover about $0.8 \mathrm{Ga}$, and more detailed studies are necessary to better document the fate of atmospheric gases in the neo-Archean before the Great Oxidation Event.

\section{Proposed solutions to the faint young Sun problem}

With the solar constant $\sim 25 \%$ weaker at $3.8 \mathrm{Ga}$ Gough, 1981], the global mean insolation absorbed by the Earth had a deficit of $\sim 60 \mathrm{~W} / \mathrm{m}^{2}\left(\sim 44 \mathrm{~W} / \mathrm{m}^{2}\right.$ at $\left.2.5 \mathrm{Ga}\right)$ compared to the current value of $240 \mathrm{~W} / \mathrm{m}^{-2}$ Wild et al. 2013. The Earth with the present atmospheric composition and continents would have undergone a cooling 
of $\sim 60 \mathrm{~K}$ (assuming the current climate sensitivity parameter of $\sim 1 \mathrm{~K}^{-\mathrm{Wm}^{-2}}$ [Flato et al. 2013] ), falling into a full glaciation. However, a glaciated early Earth is in contradiction with the evidence for liquid water and the temperate/warm climates discussed in the previous section. Moreover, once the Earth is fully ice-covered with a high surface albedo, increasing the solar constant to its present value would not be enough to exit from the snowball state Sellers, 1969, Budyko, 1969, Hoffman et al., 2017. The faint Young Sun problem becomes a paradox if we assume that the early Earth's atmosphere and continents were the same as today. But there is no argument for such an assumption. Most of the proposed solutions to the faint young Sun problem are based on changes to the atmospheric composition, clouds or land distribution, leading to a stronger greenhouse effect or a lower planetary albedo.

\section{$3.1 \mathrm{CO}_{2}$}

The first solution to the faint young Sun from Sagan and Mullen [1972] was based on a strong greenhouse effect by an ammonia-rich and highly reduced atmosphere. Such an atmosphere is now discarded in favor of a moderately-oxidized, $\mathrm{N}_{2}$ - and $\mathrm{CO}_{2}$-rich atmosphere, where the latter would be the dominant greenhouse gas Catling and Zahnle, 2020. Solving the faint young Sun problem with a high concentration of $\mathrm{CO}_{2}$ is attractive since $\mathrm{CO}_{2}$ is one of the major volatiles released from magmatic degassing Gaillard and Scaillet, 2014. Its concentration is regulated by the carbonate-silicate cycle Walker et al. 1981, which acts as a long-term thermostat on the climate. We discuss the ability of the carbonate-silicate cycle to moderate $\mathrm{CO}_{2}$ at levels required to solve the faint young Sun problem in section 5.

Previous 1D models showed that $\sim 300$ mbar of $\mathrm{CO}_{2}$ is required to maintain a global mean surface temperature of $15^{\circ} \mathrm{C}(288 \mathrm{~K})$ during the early Archean and $\sim 100$ mbar of $\mathrm{CO}_{2}$ at the late Archean Owen et al. 1979, Kasting et al. 1984; Kiehl and Dickinson, 1987; von Paris et al. 2008. Such $\mathrm{CO}_{2}$ concentrations exceed the upper limits of $\sim 30$ mbar derived from estimates of weathering of paleosols at the end of the Archean Sheldon, 2006, Driese et al. 2011. From these geological constraints and 1D climate modelling results, it has been suggested that other warming processes are needed to keep the early Earth warm.

Lessons from recent studies:

3D atmospheric GCMs coupled to simple ocean/sea-ice models found that lower amounts of $\mathrm{CO}_{2}$ are needed to maintain global mean surface temperatures of $15^{\circ} \mathrm{C}$ during the Archean (see Fig. 1 and Wolf and Toon
2013 ; Charnay et al. 2013]). According to the model from Wolf and Toon 2014, 200 mbar of $\mathrm{CO}_{2}$ is required at $3.8 \mathrm{Ga}$ and $40 \mathrm{mbar}$ at $2.5 \mathrm{Ga}$ (see Fig. 2). The case of a warm early Earth with a mean surface temperature of $60-80^{\circ} \mathrm{C}$ is achievable with high levels of $\mathrm{CO}_{2}$ around $0.5-1$ bar according to the 3D study from Charnay et al. 2017, which is significantly less than previous 1D estimations of $\sim 3$ bars of $\mathrm{CO}_{2}$ at $3.3 \mathrm{Ga}$ by Kasting and Howard 2006. These discrepancies are mostly related to cloud feedbacks (see section 4 ), leading to warmer climates with $3 \mathrm{D}$ models. The amounts of $\mathrm{CO}_{2}$ required for temperate climates from 3D models are above the geological limits from Sheldon 2006. and Driese et al. 2011. However, we point out the fact that revised paleosol $\mathrm{pCO}_{2}$ estimates exist, as discussed in the previous section. If the recent $\mathrm{pCO}_{2}$ limits from Kanzaki and Murakami 2015 are correct, temperate climates would be achievable with just enhanced $\mathrm{CO}_{2}$ (see Fig. 2). The $\mathrm{pCO}_{2}$ required for an early Earth at $60-80^{\circ} \mathrm{C}$ would still remain too high, compatible with only one data point from Kanzaki and Murakami 2015. and with the constraint from Lehmer et al. [2020].

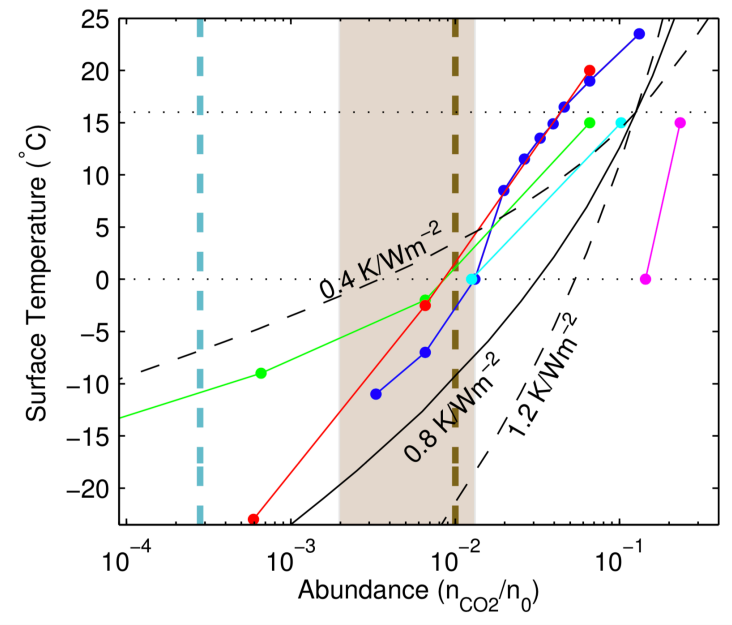

Fig. 1 Mean surface temperature as a function of $\mathrm{CO}_{2}$ abundance for $0.8 \mathrm{~S}_{0}$. The results of the $1 \mathrm{D}$ models from HaqqMisra et al. 2008, (green) and von Paris et al. 2008 (cyan) are shown, as well as the 3D models from Wolf and Toon 2013 (blue), Charnay et al. 2013. (red), as well as a 3D oceanic model with a simplified atmospheric model from Kienert et al. 2012] (magenta). The shaded region shows the $\mathrm{CO}_{2}$ constraint range from Driese et al. 2011. The vertical dashed blue and brown lines give the pre-industrial and early Earth guess $\left(10^{-2}\right)$ abundances of $\mathrm{CO}_{2}$. Figure from Byrne and Goldblatt 2014. 


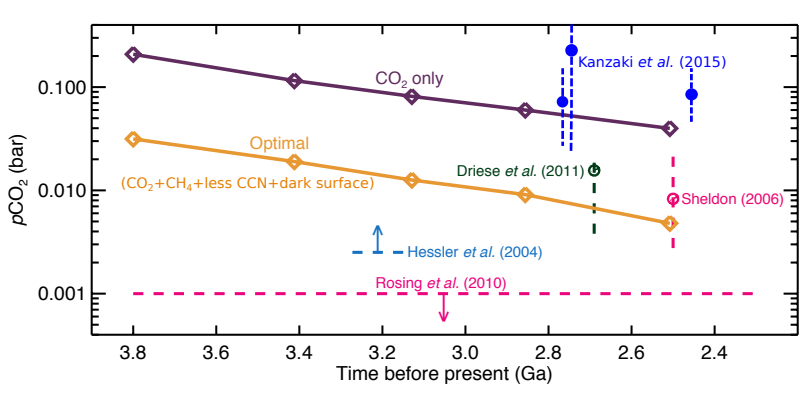

Fig. 2 The amount of $\mathrm{CO}_{2}$ needed to maintain global mean surface temperatures of $288 \mathrm{~K}$ over the course of the Archean for several different scenarios. Optimal warming scenarios include 0.1 mbar of $\mathrm{CH}_{4}$, an 18 hour rotation rate, a dark soil surface, and reduced cloud droplet number concentrations. Figure adapted from Wolf and Toon 2014.

\section{$3.2 \mathrm{CH}_{4}$}

Methane has been suggested as an important complement to $\mathrm{CO}_{2}$ to warm the early Earth Kiehl and Dickinson, 1987, Pavlov et al. 2000]. Photochemical models predict that $\mathrm{CH}_{4}$ had a lifetime typically 1000 times longer in the anoxic Archean atmosphere than in the present-day atmosphere Zahnle, 1986, Kasting and Howard 2006. Abiotic sources of $\mathrm{CH}_{4}$ like serpentinization in hydrothermal vents could have maintained concentrations up to $\sim 2.5 \mathrm{ppm}$ Tian et al. 2011; Guzmán-Marmolejo et al. 2013. Biogenic $\mathrm{CH}_{4}$ flux from methanogens could have maintained much higher concentrations between 0.1 mbar and 35 mbar Kharecha et al. 2005, Ozaki et al. 2018; Krissansen-Totton et al., 2018b; Schwi-

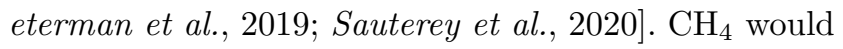
have been produced by $\mathrm{H}_{2}$-based methanogens or by fermentors and acetotrophs decomposing the biomass produced by phototrophs $\left(\mathrm{H}_{2}\right.$-based phototrophs and ferrophototrophs). In addition, the fractionation of atmospheric Xenon could be explained by hydrodynamic hydrogen escape during the Hadean/Archean if the $\mathrm{H}_{2}$ mixing ratio was higher than $1 \%$ or if the $\mathrm{CH}_{4}$ mixing ratio was higher than $0.5 \%$ (i.e. 5 mbar for a 1-bar surface pressure) Zahnle et al., 2019. Such high concentrations of $\mathrm{CH}_{4}$ produce a strong greenhouse by absorbing thermal radiation at $7-8 \mu \mathrm{m}$, the edge of an atmospheric window for a $\mathrm{CO}_{2}-\mathrm{H}_{2} \mathrm{O}$ atmosphere Kiehl and Dickinson, 1987, Pavlov et al., 2000, Haqq-Misra et al., 2008.

A limitation appears for high methane concentrations due to the formation of organic hazes. Organic hazes are expected to form when the $\mathrm{CH}_{4} / \mathrm{CO}_{2}$ ratio becomes higher than $\sim 0.2$ according to photochemical models and experimental data Zerkle et al. 2012 ; Trainer et al. 2006. There is possible isotopic evidence of organic haze formation at $2.7 \mathrm{Ga}$ Zerkle et al. 2012. Hazes are expected to cool the surface by absorbing UV and visible solar radiation, which produces an antigreenhouse effect Pavlov et al., 2001, Haqq-Misra et al. 2008. Although, 1D simulations that incorporate the fractal aggregate nature of haze particles suggest that this cooling effect may not be as large as previously thought Wolf and Toon, 2010, Arney et al., 2016. In addition, fractal haze particles act as a UV shield, protecting both life and photolytically unstable reduced gases Wolf and Toon, 2010.

Finally, it has been argued that the Great Oxidation Event caused a large decline in atmospheric methane concentration, triggering the Huronian glaciations Pavlpv et al., 2000, Kasting and Ono, 2006, Goldblatt et al., 2006. The apparent synchronicity of the two events at $\sim 2.4 \mathrm{Ga}$ is an additional argument in favour of a methane-rich Archean atmosphere.

Lessons from recent studies:

Fig. 3 shows the global mean warming by $\mathrm{CH}_{4}$ from a $3 \mathrm{D}$ GCM. It reaches up to $\sim+14 \mathrm{~K}$ for $\mathrm{pCH}_{4}=1 \mathrm{mbar}$. However, the warming decreases for $\mathrm{pCH}_{4}>1$ mbar. That is due to the absorption of near-IR solar radiation by $\mathrm{CH}_{4}$ in the stratosphere, producing an anti-greenhouse effect Byrne and Goldblatt, 2014. That cooling appears in radiative transfer code using HITRAN 2008 or more recent versions. Most of previous 1D studies of the early Earth as Kiehl and Dickinson 1987]; Pavlov et al. 2000; Haqq-Misra et al. [2008] used older databases and overestimated the greenhouse effect for high concentrations of $\mathrm{CH}_{4}$. That effect poses a strong limitation to solutions to the faint young Sun problem based primarily on a $\mathrm{CH}_{4}$ greenhouse. Despite the limitations at high conceterations, $\mathrm{CH}_{4}$ greenhouse is an excellent complement to $\mathrm{CO}_{2}$ to solve the faint young Sun problem, filling up to $20 \%$ of the radiative forcing deficit Byrne and Goldblatt, 2014. However, it cannot be significant in prebiotic time, meaning that $\mathrm{CO}_{2}$ greenhouse and other abiotic processes likely maintained liquid surface water before the emergence of methanogenesis.

3.3 Other greenhouse gases $\left(\mathrm{NH}_{3}, \mathrm{H}_{2}\right)$ and atmospheric pressure

As mentioned previously, Sagan and Mullen 1972 proposed an ammonia $\left(\mathrm{NH}_{3}\right)$ greenhouse as a solution to the faint young Sun problem. However, $\mathrm{NH}_{3}$ is quickly photolyzed and cannot reach concentrations high enough to compensate for the faint young Sun. Yet, UV shielding by photochemical organic hazes could significantly extend the lifetime of $\mathrm{NH}_{3}$ [Wolf and Toon, 2010]. 3D simulations coupling chemistry and haze microphysics 


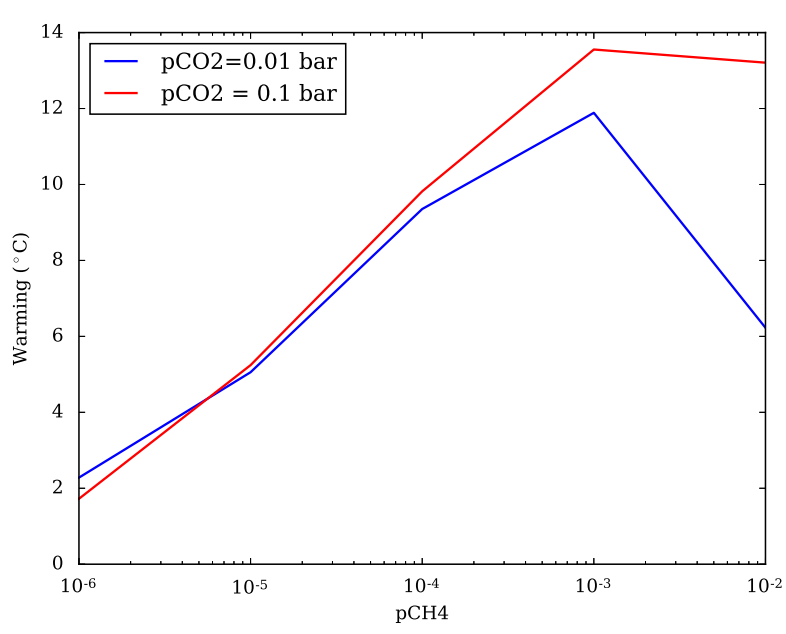

Fig. 3 Global mean warming by methane as a function of $\mathrm{pCH}_{4}$ (in bar) for an atmosphere with 0.01 bar (blue) and 0.1 bar (red) of $\mathrm{CO}_{2}$ at $3.8 \mathrm{Ga}$. Simulations done with the Generic LMD GCM using HITRAN 2008 for $\mathrm{CH}_{4}$ opacity Charnay et al. 2017.

will be required to verify if hazes can adequately protect $\mathrm{NH}_{3}$ from photolysis. In any case, an $\mathrm{NH}_{3}$ greenhouse appears as a limited solution to the faint young Sun problem, requiring a very reduced early atmosphere or high levels of biogenic $\mathrm{CH}_{4}$.

$\mathrm{N}_{2}$ has no electric dipole and interacts weakly with electromagnetic field, making it a poor greenhouse gas. However, it can enhance the greenhouse effect of others gases by pressure broadening. A high pressure also increases the surface temperature by increasing the moist adiabatic lapse rate, resulting in decreased convective heat transport. Goldblatt et al. 2009] found that 23 times more atmospheric $\mathrm{N}_{2}$ would have produced a warming of $+3-8 \mathrm{~K}$, allowing more clement conditions for the early-Earth with a $\mathrm{CO}_{2}$-poor atmosphere. At high pressure, $\mathrm{N}_{2}$ and $\mathrm{H}_{2}$ can absorb thermal radiation through collision-induced absorption (CIA). CIA of $\mathrm{N}_{2-}$ $\mathrm{N}_{2}, \mathrm{H}_{2}-\mathrm{N}_{2}$ and $\mathrm{N}_{2}-\mathrm{CH}_{4}$ are responsible for most of the greenhouse effect on Titan McKay et al. 1991, while $\mathrm{H}_{2}-\mathrm{H}_{2}$ and $\mathrm{H}_{2}$-He play a significant role in the thermal structure of giant planets. Wordsworth and Pierrehumbert 2013 suggested that the early Earth could have been warmed by $\mathrm{N}_{2}-\mathrm{H}_{2}$ CIA. This warming process strongly depends on the amount of $\mathrm{N}_{2}$ and $\mathrm{H}_{2}$. It becomes efficient $(>+10 \mathrm{~K})$ for a $\mathrm{N}_{2}$ mass column of 2-3 times higher than today and $\mathrm{H}_{2}$ mixing ratio of 0.1. A model by Tian et al. 2005, suggested that the $\mathrm{H}_{2}$ mixing ratio could have been as high as 0.3 in the anoxic early Earth's atmosphere, due to a weaker Jean atmospheric escape.

Lessons from recent studies:
A recent modelling work by Kuramoto et al. 2013. shows that atmospheric escape almost reached the diffusion limited regime during this time period. This implies a $\mathrm{H}_{2}$ mixing ratio lower than 0.01 for realistic $\mathrm{H}_{2}$ volcanic fluxes. The existence of detrital magnetite grains in Archean sandstones also suggests a low $\mathrm{H}_{2}$ mixing ratio with $\mathrm{pH}_{2}<10$ mbar Kadoya and Catling. 2019]. Moreover, the previous two warming processes, pressure broadening by increased $\mathrm{N}_{2}$ and $\mathrm{N}_{2}-\mathrm{H}_{2}$ CIA, both require a $\mathrm{N}_{2}$ mass column 2-3 times higher in the past. Such a high surface pressure is not consistent with geological and isotopic constraints discussed in section 2.5. We conclude that a warming by $\mathrm{NH}_{3}, \mathrm{~N}_{2}-\mathrm{H}_{2}$ or a higher atmospheric pressure probably did not operate during the Archean. The situation might have been different during the Hadean. In particular, the partial pressure of $\mathrm{N}_{2}$ was likely higher in the Hadean when nitrogen fixation was limited to abiotic processes Stüeken et al. 2015, 2016. An episodic reduced $\mathrm{H}_{2}$-rich atmosphere could also have been formed for 10-20 Myrs after giant impacts caused during the late veneer, by reduction of water by a molten iron impactor Benner et al. 2020.

\subsection{A lower albedo due to less continent and cloud feedbacks}

A lower planetary albedo due to a change in the cloud cover and emerged land has been suggested several times as a potential contributor to solve the faint young Sun problem Jenkins et al. 1993, Rosing et al., 2010. To fully compensate for a $20-25 \%$ lower insolation, the planetary albedo would have to be $\sim 0.05-0.1$ (similar to Mercury or the Moon) compared to 0.29 for the presentday Earth Wild et al., 2013. Even by removing of all emerged land and all clouds, such a low value would not be reached because of atmospheric Rayleigh scattering. Still, a change in the cloud cover or thickness and fraction of emerged land could have been part of the solution to the faint young Sun problem.

As explained before, the fraction of emerged land is expected to have been lower during the Archean, likely between 2 and $12 \%$ of Earth's surface Flament et al. 2008. Furthermore, what emergent continents did exist were likely barren of vegetation, and probably were composed of dark basalts, before gradually changing into the lighter-colored soils we see today as they aged. A reduction of surface albedo would give a maximal radiative forcing of $\sim+5 \mathrm{~W} / \mathrm{m}^{2}$ Goldblatt and Zahnle, 2011b.

Clouds have a strong impact on the terrestrial radiative budget by reflecting solar radiation and by absorbing thermal radiation. The albedo effect (cooling ef- 
fect) dominates for lower clouds, such as stratus clouds while the greenhouse effect (warming effect) dominates for upper clouds, such as cirrus clouds. Rondanelli and Lindzen 2010 suggested that the amount of tropical cirrus formed by detrainment from convective clouds would increase under a fainter Sun, enhancing their greenhouse effect and maintaining a clement climate. Such a negative feedback, called the "Iris hypothesis" Lindzen et al. 2001, remains debated Goldblatt and Zahnle, 2011a| Mauritsen and Stevens, 2015 and could also be compensated or dominated by other positive cloud feedbacks Bony and Dufresne, 2005; Bony et al., 2015. A more plausible hypothesis is that lower clouds were optically thinner during the Archean, owing to the lack of cloud condensation nuclei $(\mathrm{CCN})$ from biological sources. Such a decrease of CCN yields larger cloud particles which are less effective at scattering and precipitate faster, resulting in a decrease of the planetary albedo Rosing et al. 2010. The removal of all lower clouds compared to the present-day cover would lead to a radiative forcing of $\sim 25 \mathrm{~W} / \mathrm{m}^{2}$ Goldblatt and Zahnle, 2011a.

Lessons from recent studies:

3D GCMs have shown that plausible reductions to the surface albedo and emerged land fraction could have increased the global mean surface temperature by up to $+4 \mathrm{~K}$ Wolf and Toon, 2013; Charnay et al., 2013. They also suggest that a reduction in $\mathrm{CCN}$ results in an increase of the cloud radiative forcing of up to $\sim+12$ $\mathrm{W} / \mathrm{m}^{2}$, and an increases in the global mean surface temperature of up to $10 \mathrm{~K}$ Charnay et al. 2013; Wolf and Toon, 2014]. A similar temperate change by CCN was found for the Neoproterozoic by Feulner et al. 2015. Independent of the $\mathrm{CCN}$ effect, GCMs indicate that a reduced cover of lower clouds and a increased cover of higher clouds for enhanced $\mathrm{CO}_{2}$ and weaker insolation, providing an additional radiative forcing of $\sim+5$ $\mathrm{W} / \mathrm{m}^{2}$ (see section 4.2 and Wolf and Toon 2013; Charnay et al. 2013). In conclusion, a change in the land and cloud cover together cannot compensate more than $60 \%$ of the deficit of radiative forcing due to the weaker Archean Sun. A higher amount of greenhouse gases (i.e. $\mathrm{CO}_{2}$ and $\mathrm{CH}_{4}$ ) is still required. However, a reduction to the cloud and surface albedos may have meaningfully contributed to warming the early Earth, and thus less $\mathrm{CO}_{2}$ and $\mathrm{CH}_{4}$ may have been otherwise required.

\section{New insights from 3D climate models}

\subsection{Testing the proposed warming solutions with 3D GCMs}

While 3D GCMs are notoriously computationally expensive to run, recent gains in computing availability and parallel processing now allow GCMs to be run with sufficient speed to facilitate a wide variety of planetary modelling studies. As such, atmospheric GCMs with simplified ocean/sea-ice components have now been used to thoroughly explore the climate history of the ancient Earth, from the early Archean up through recent snowball Earth epochs Jenkins and Smith, 1999, Pierrehumbert, 2004, Charnay et al., 2013; Wolf and Toon, 2013, 2014, Le Hir et al., 2014, Kunze et al., 2014 Teitler et al., 2014, Charnay et al., 2017; Wolf et al. 2018. The use of such 3D climate models has allowed us explore the numerous alternative climatological mechanisms for warming the early Earth despite the faint young Sun and described in section 3 .

As explained in the former section, these models have shown that enhanced $\mathrm{CO}_{2}$ likely played the major role and could have compensated the fainter Sun with $\mathrm{pCO}_{2} \sim 40$ mbar at $2.5 \mathrm{Ga}$. Such a concentration is above the limits from Sheldon 2006 and Driese et al. 2011 but compatible with the constraints from Kanzaki and Murakami 2015 (see Fig. 2).Note that the case of a warm early Earth with a mean surface temperature of $60-80^{\circ} \mathrm{C}$ is achievable with high levels of $\mathrm{CO}_{2}$ around 0.5-1 bar Charnay et al. 2017. However, the $\mathrm{pCO}_{2}$ required in that case is only compatible with one data point from Kanzaki and Murakami 2015 (i.e. $\mathrm{pCO}_{2}=22-700$ mbar at $\left.2.75 \mathrm{Ga}\right) . \mathrm{CH}_{4}$ could have been a significant contributor to warm the Archean Earth, increasing the global mean surface temperature by up to $+14 \mathrm{~K}$ for $\mathrm{pCH}_{4}=1 \mathrm{mbar}$ (see Fig. 3 and Wolf and Toon, 2013]).

Plausible reductions to the surface albedo or emerged land fraction could have warm the planet by up to $+4 \mathrm{~K}$ Charnay et al. 2013, Wolf and Toon, 2014. A reduction of emerged land fraction does not necessarily imply a lower planetary albedo because cloud cover tends to decrease above continents compared with over oceans. But this cooling effect is compensated by a stronger evaporation leading to an increase in the amount of water vapour in the atmosphere and thus a stronger greenhouse effect Charnay et al. 2013.

GCMs suggest that increases in the global mean surface temperature of up to $+10 \mathrm{~K}$ are possible to due to reductions in $\mathrm{CCN}$ and the resulting feedbacks on clouds. The models predict that there are globally less low clouds (i.e., lower than $5 \mathrm{~km}$ ), which are in addi- 
tion optically thinner, for low and middle latitudes with less CCN. However, there are also more low clouds at high latitudes and more high clouds (i.e., higher than $5 \mathrm{~km}$ ), because of the warmer climate with a more extended Hadley cell. According to Wolf and Toon 2013 and Charnay et al. [2013], the warming is dominated by the decrease of low clouds and the shortwave forcing (albedo effect). In the model by Le Hir et al. [2014, the cloud feedback is dominated by the increase of high clouds and the longwave radiative forcing (greenhouse effect). We note that Le Hir et al. [2014] used a parametrisation for the precipitation rate more sensitive to cloud particle size than Wolf and Toon 2013 and Charnay et al. 2013, which may explain the difference.

If the background $\mathrm{N}_{2}$ partial pressure of the Archean was 2 to 3 times greater than today, as postulated by Goldblatt et al. 2009], then the Archean may have been warmed by +5 to $+10 \mathrm{~K}$ for a given amount of $\mathrm{CO}_{2}$ according to these 3D models. However and as explained in section 2.5, some geological/geochemical analyses indicate that the total nitrogen content of the Archean atmosphere should have been similar or smaller than the present day Som et al., 2012, Marty et al., 2013; Som et al., 2016].

The early Earth had a faster rotation rate than the present-day Earth, with a diurnal period possibly as short as 10 hours Zahnle and Walker, 1987, Williams, 2000, Bartlett and Stevenson, 2016]. Changing the rotation would subtly affect horizontal heat transports. A faster rotation rate limits the size of eddies as well as the latitudinal extension and the strength of the Hadley cells. All these changes reduce the efficiency of meridional transport. Under such conditions, the equatorpole thermal gradient is enhanced with a warmer equator and cooler poles, sea ice is more extended and zonal jets are closer to the equator. However this has been shown not to have a significant effect on the overall climate state, with just a small warming of $\sim+1 \mathrm{~K}$ Charnay et al., 2013, Wolf and Toon, 2014, Le Hir et al., 2014. Note that these studies use simple ocean models, with no sea-ice transport and with a fixed oceanic heat diffusivity. Charnay et al. 2013 use a 2-layer ocean model with Ekman transport coupled to surface winds. This allows to more properly simulate meridional heat transport at low latitude, but the model still misses the sea-ice transport. In contrast, simulations by Kienert et al. 2012 with a 3D oceanic model and a simplified $2 \mathrm{D}$ atmospheric model suggest a strong cooling for a fast rotation rate. This is caused by a reduced atmospheric and oceanic heat transport as well as by a change in cloud cover and lapse rate. The latter is likely an artefact of the parametrisation used in the $2 \mathrm{D}$ atmospheric model and the cooling is likely overestimated (see the discussion in Le Hir et al. 2014]). However, the change in ocean dynamics may have a non-negligeable impact on the global mean surface temperature. This has to be explored with a full 3D atmosphere-ocean GCM.

Table 1 summarises the different proposed solutions to the faint young Sun problem, the radiative forcing (computed from 1D or 3D models) and the constraints (geological, geochemical or theoretical). Solutions which are compatible with geological/geochemical constraints are in green, possible solutions for which there is only theoretical constraints are in yellow and solutions which are not compatible with the constraints are in red. While many researchers have sought to find sweeping solutions to the faint young Sun problem, perhaps the paradox is instead solved by a collection of the processes outlined above. Coupled with enhanced $\mathrm{CO}_{2}$, increased $\mathrm{CH}_{4}$, reductions to the cloud albedo, and a dark surface, all can contribute +4 to $+14 \mathrm{~K}$ of global mean warming. Note that the cumulated radiative forcing (i.e. global warming) is not necessary equal to the sum of each process taken separately. For instance, gases and high ice clouds can have overlapping greenhouse effects. 3D studies now suggest that there are plausible solutions for maintaining temperate climates within geological constraints on surface temperature and $\mathrm{CO}_{2}$, combining these different warming processes. In particular, Charnay et al. 2013] and Wolf and Toon 2013 using structurally similar but independently constructed 3D climate models with different boundary conditions (i.e. land distribution), both found that mean surface temperatures similar to that of the present day Earth can be maintained at the end of the Archean $(2.5 \mathrm{Ga})$, provided that the atmosphere had: 1) 40 mbar $\left.\mathrm{CO}_{2}, 2\right)$ 10-20 mbar $\mathrm{CO}_{2}$ and 1-2 mbar $\mathrm{CH}_{4}$ or 3) 5 mbar $\mathrm{CO}_{2}, 0.1$ mbar of $\mathrm{CH}_{4}$, reduced $\mathrm{CCN}$ and dark soil surface. The yellow curve in the figure 2 shows the amount of $\mathrm{CO}_{2}$ needed to maintain global mean surface temperatures of $15^{\circ} \mathrm{C}$ considering the case where multiple warming mechanisms are factored in $(0.1 \mathrm{mbar}$ of $\mathrm{CH}_{4}$, reduced $\mathrm{CCN}$ and dark soil surface). The combination of all these processes is totally plausible for the Archean. For this optimal case, a temperate Earth can be maintained at all times of the Archean with $\mathrm{CO}_{2}$ amounts less than 30 mbar, compatible with constraints from Sheldon 2006] and Driese et al. 2011.

Finally, the similar results obtained from these different 3D GCMs with simplified ocean/sea-ice models, in particular the similar $\mathrm{pCO}_{2}$ required for temperate climates, suggest that the faint young Sun problem can be solved more easily than initially thought. Even the case of a warm early Earth at $60^{\circ} \mathrm{C}$ is more accessible from a purely climate modelling point of view, although 
not compatible with most of geological constraints on $\mathrm{pCO}_{2}$ and surface pressure.

\subsection{Cloud feedbacks}

Fig. 1 shows global mean surface temperature as a function of $\mathrm{pCO}_{2}$ from two 1D models Haqq-Misra et al. 2008 von Paris et al. 2008 and two GCMs [Wolf and Toon, 2013: Charnay et al., 2013 for a 20\% weaker Sun (i.e $3 \mathrm{Ga}$ ). While all models predict a $\mathrm{pCO}_{2}$ around 10 mbar for a global mean surface temperature of $0^{\circ} \mathrm{C}$, the 3D GCMs show a higher climate sensitivity $(\sim 1$ $\mathrm{K} / \mathrm{Wm}^{-2}$ in $3 \mathrm{D}$ versus $\sim 0.6 \mathrm{~K} / \mathrm{Wm}^{-2}$ in $1 \mathrm{D}$ ), reaching a present-day like mean temperature for half the $\mathrm{pCO}_{2}$ from 1D model. This higher value is mostly due to feedbacks from sea-ice and clouds, not present in 1D models. The climate sensitivity obtained in these 3D studies is similar to the climate sensitivity of GCMs used for the IPCC report, giving a value of $1 \pm 0.5 \mathrm{~K} / \mathrm{Wm}^{-2}$ Flato et al. 2013.

For a similar global mean surface temperature, a high $\mathrm{pCO}_{2}$ and a fainter Sun result in a weaker equatorpole temperature gradient, a lower surface evaporation rate and a higher tropopause. The evaporation is reduced by around $7 \%$ for the Archean Earth with presentday like temperatures Wolf and Toon, 2013. Moreover, enhanced $\mathrm{CO}_{2}$ reduces the radiative cooling of low clouds and thus reduces their efficiency to form. Both the weaker evaporation rate and the weaker radiative cooling lead to a reduced fraction of low clouds for the Archean Earth Wolf and Toon, 2013, Charnay et al. 2013. In addition, 3D GCMs predict an increase of the cover and altitude of high clouds, due to a more extended troposphere and a colder tropopause for a $\mathrm{CO}_{2}$-rich atmosphere with no ozone. The decrease of low clouds and the increase of high clouds increases the net cloud radiative forcing. Fig. 4 and Fig. 5 illustrates the change in cloud cover and temperature for the Archean Earth. 3D models predict a net cloud radiative forcing increased by around $+15 \mathrm{~W} / \mathrm{m}^{2}$ for a temperate Archean Earth with 60 mbar of $\mathrm{CO}_{2}$ Wolf and Toon, 2013. This increase also takes into account the reduction of the insolation in the past and cannot be added directly to other forcings to compensate for the deficit of absorbed solar radiation. A more proper calculation can be done using the insolation at $3.8 \mathrm{Ga}$ for the shortwave forcing for both the early Earth and the present-day Earth. In this case, the change in the cloud cover increases the net cloud radiative forcing by around $+5 \mathrm{~W} / \mathrm{m}^{2}$. This means that the cloud feedbacks enhance the $\mathrm{CO}_{2}$ warming by $\sim 11 \%$. If we use instead the current insolation for the shortwave forcing (what will be useful for the following comparison with IPCC simulations), we found an increase of the net cloud radiative forcing by around $+7 \mathrm{~W} / \mathrm{m}^{2}$, or $\sim 16 \%$ of the $\mathrm{CO}_{2}$ warming.

A similar positive cloud feedback due to high clouds and a reduced cover of low clouds for increasing $\mathrm{pCO}_{2}$ is present in most of 3D GCMs used for climate change (see Boucher et al. 2013 and references therein). To compare the cloud feedbacks for the Archean Earth (for which the reduced insolation is balanced by enhanced $\mathrm{CO}_{2}$ ) to GCMs used for current climate change, it is appropriate to consider rapid adjustments, that is after the $\mathrm{CO}_{2}$ is increased but before the ocean temperatures have fully adjusted. This avoids to include contributions due to the change in the sea surface temperature. Zelinka et al. 2013 found that the net cloud forcing increases by $\sim 1.1 \mathrm{~W} / \mathrm{m}^{2}$ in simulations from $5 \mathrm{GCMs}$ after an abrupt quadrupling of $\mathrm{CO}_{2}$. Since the forcing for $4 \times \mathrm{CO}_{2}$ is around $7.4 \mathrm{~W} / \mathrm{m}^{2}$ Boucher et al. 2013, cloud feedbacks enhance the $\mathrm{CO}_{2}$ warming by $\sim 15 \%$, similar to our estimate for the Archean Earth using current insolation. We conclude that the cloud feedbacks in 3D simulations of the Archean Earth are similar and consistent with 3D simulations for anthropogenic climate change. Note that the spread between different climate models is large, in particular for the cloud forcing which remain one of the largest sources of uncertainty in climate modelling.

The effects of cloud feedbacks is particularly strong for warm/hot climates. Archean climates with mean surface temperature around $60^{\circ} \mathrm{C}$ are obtained with $\sim 1$ bar of $\mathrm{CO}_{2}$ according to the 3D model of Charnay et al. 2017. This is 3 times less than predictions from the 1D model of Kasting and Howard 2006. This discrepancy mostly comes from the strong decrease of lower clouds for high levels of $\mathrm{CO}_{2}$. The net cloud forcing is increased by $\sim+10-15 \mathrm{~W} / \mathrm{m}^{2}$ for a warm climate $\left(\mathrm{pCO}_{2}=1\right.$ bar $)$ compared to a temperate climate $\left(\mathrm{pCO}_{2}=0.1\right.$ bar $)$ Charnay et al. 2017. This corresponds to an increase of $\sim+25 \mathrm{~W} / \mathrm{m}^{2}$ compared to the presentday cloud forcing. Under high $\mathrm{pCO}_{2}$, increasing the size of cloud particles has a limited effect $\left(<+3 \mathrm{~W} / \mathrm{m}^{2}\right)$, suggesting that the planet has almost reached the maximal cloud forcing related to the reduction of low clouds.

\subsection{The case of cold climates with waterbelts}

With fairly small $\mathrm{CO}_{2}$ amounts ( $<1$ mbar), 3D models with simplified ocean predict that the early Earth would have been cold $\left(\mathrm{T}<0^{\circ} \mathrm{C}\right)$ but would have avoided complete glaciation, instead maintaining an equatorial icefree waterbelt Charnay et al., 2013; Wolf and Toon, 2013: Le Hir et al., 2014, Kunze et al., 2014, Teitler et al. 2014. For these cold climates, the mean surface 


\begin{tabular}{|c|c|c|c|}
\hline $\begin{array}{l}\text { Solutions to the } \\
\text { FYS problem }\end{array}$ & Maximal radiative forcing & $\begin{array}{l}\text { Constraints } \\
\text { (paleosols or theoretical) }\end{array}$ & References for constraints \\
\hline \multirow[t]{5}{*}{ Elevated $\mathrm{CO}_{2}$} & $\begin{array}{l}+26 \mathrm{Wm}^{-2}\left(\text { for } \mathrm{pCO}_{2}=10 \mathrm{mbar}\right) \\
+44 \mathrm{Wm}^{-2}\left(\text { for } \mathrm{pCO}_{2}=60 \mathrm{mbar}\right)\end{array}$ & $\begin{array}{l}\mathrm{pCO}_{2}=3-15 \operatorname{mbar}(2.69 \mathrm{Ga}) \\
\mathrm{pCO}_{2}=3-25 \operatorname{mbar}(2.5 \mathrm{Ga})\end{array}$ & \begin{tabular}{|l|} 
Driese et al. \\
Sheldon, 2011 \\
\end{tabular} \\
\hline & & $\mathrm{pCO}_{2}=24-140 \operatorname{mbar}(2.77 \mathrm{Ga})$ & Kanzaki and Murakami \\
\hline & Wolf and Toon, 2013 & $\mathrm{pCO}_{2}=22-700 \operatorname{mbar}(2.75 \mathrm{Ga})$ & Kanzaki and Murakami, 2015 \\
\hline & Le Hir et al., 2014 & $\mathrm{pCO}_{2}=45-140 \operatorname{mbar}(2.46 \mathrm{Ga})$ & Kanzaki and Murakami, 2015 . \\
\hline & Byrne and Goldblatt, 2014 & $\mathrm{CO}_{2}>70 \%(2.7 \mathrm{Ga})$ & Lehmer et al. 2020 \\
\hline \multirow[t]{3}{*}{ Elevated $\mathrm{CH}_{4}$} & $+9 \mathrm{Wm}^{-2}\left(\right.$ for $\left.\mathrm{pCH}_{4}=1 \mathrm{mbar}\right)$ & $\mathrm{pCH}_{4}=0.01-10$ mbar & Sauterey et al. 2020 \\
\hline & Byrne and Goldblatt, 2014 & $\mathrm{CH}_{4}>0.5 \%(\sim 3.5 \mathrm{Ga})$ & Zahnle et al. 2019 \\
\hline & Le Hir et al. ' 2014 & $\mathrm{CH}_{4}: \mathrm{CO}_{2} \sim 0.2(\sim 2.6 \mathrm{Ga})$ & Zerkle et al. 2012 \\
\hline \multirow[t]{2}{*}{ Less emerged land } & $+5 \mathrm{Wm}^{-2}$ (with almost no land) & Fraction $=2-12 \%(2.5 \mathrm{Ga})$ & Flament et al. $\overline{2008}$ \\
\hline & Goldblatt and Zahnle, 2011a & Crust volume $=60-80 \%(3 \mathrm{Ga})$ & Hawkesworth et al. 2019 \\
\hline \multirow[t]{2}{*}{ Faster rotation } & $\sim+0 \mathrm{Wm}^{-2}($ for $\mathrm{P}=14 \overline{\mathrm{h}})$ & \multirow{2}{*}{$\begin{array}{l}\text { Length of day }=21.9 \pm 0.4 \mathrm{~h}(620 \mathrm{Ma}) \\
\text { Length of day } \sim 13 \mathrm{~h}(3.8 \mathrm{Ga})\end{array}$} & Williams, 2000 \\
\hline & Charnay et al. 2013 & & Bartlett and Stevenson 2016 \\
\hline $\begin{array}{l}\text { Cloud feedbacks and } \\
\text { less CCN }\end{array}$ & 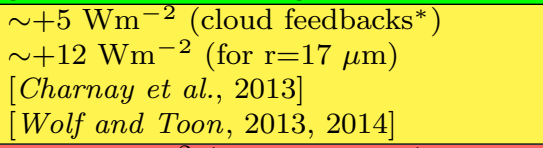 & Larger droplets $(\mathrm{r} \sim 17 \mu \mathrm{m})$ & $\overline{\text { Rosing et al. }} \overline{2010}$ \\
\hline High surface pressure & $\begin{array}{l}+12.2 \mathrm{Wm}^{-2}\left(\text { for } 2 \times \overline{\mathrm{P}} \overline{\mathrm{N}}_{2}\right) \\
\text { Goldblatt et al. } 2009\end{array}$ & $\begin{array}{l}\mathrm{P}=0.23 \pm 0.23 \text { bar }(2.74 \mathrm{Ga}) \\
\mathrm{P}<0.53-1.1 \text { bar }(2.7 \mathrm{Ga})\end{array}$ & \begin{tabular}{|l|l|} 
Som et al. & 2016 \\
Som et al. & 2012 \\
\end{tabular} \\
\hline $\mathrm{N}_{2}-\mathrm{H}_{2}$ warming & $\begin{array}{l}+24 \mathrm{Wm}^{-4}\left(\text { for } 3 \times \mathrm{PAL} \mathrm{N}_{2}, 10 \% \mathrm{H}_{2}\right) \\
\text { Wordsworth and Pierrehumbert, } 2013\end{array}$ & $\begin{array}{l}\mathrm{pN}_{2}<1.1 \text { bar }(3.5-3 \mathrm{Ga}) \\
\mathrm{pN}_{2}<1 \text { bar }(3.3 \mathrm{Ga}) \\
\mathrm{pH}_{2}<10 \text { mbar } \\
\mathrm{H}_{2}<1 \%\end{array}$ & \begin{tabular}{|l|l|} 
Marty et al. & 2013 \\
Avice et al. & 2018 \\
Kadoya and Catling, & 2019 \\
Kuramoto et al. & 2013 \\
\end{tabular} \\
\hline Elevated $\mathrm{NH}_{3}$ & $\begin{array}{l}+33 \mathrm{Wm}^{-2} \text { (for } \mathrm{pNH}_{3}=10^{-2} \text { mbar) } \\
\text { Byrne and Goldblatt, } 2014\end{array}$ & $\begin{array}{l}\mathrm{pNH}_{3} \sim 10^{-5} \text { mbar } \\
\text { Higher values if organic hazes }\end{array}$ & 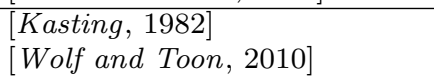 \\
\hline
\end{tabular}

Table 1 Table of solutions to the Faint Young Sun Problem. The first column lists the different possible solutions. The second column gives the maximal radiative forcing and the corresponding references based on $1 \mathrm{D}$ or $3 \mathrm{D}$ models. We remind that the faint young Sun implies a deficit of $44 \mathrm{Wm}^{-2}$ at $2.5 \mathrm{Ga}$ and $60 \mathrm{Wm}^{-2}$ at $3.8 \mathrm{Ga}$. For $\mathrm{CO}_{2}$, we give the forcing for two values of $\mathrm{pCO}_{2}$ consistent with the different constraints. ${ }^{*}$ The change in the cloud radiative forcing is computed for the insolation at $3.8 \mathrm{Ga}$, between the Archean cloud cover and the present-day cloud cover. The third and fourth columns show the constraints from paleosols or models for the different solutions with the references (see also table 1 in Catling and Zahnle 2020]). We indicate here the prominent recent constraints. Green is for solutions and radiative forcings which are compatible with the constraints, yellow for possible solutions for which there are only theoretical constraints, and red for solutions which are not compatible with the constraints.

temperature is lower than predicted by $1 \mathrm{D}$ models (see for instance Fig. 1). Fig. 6 shows the mean latitudinal extent of polar sea ice as a function of $\mathrm{pCO}_{2}$ from $3 \mathrm{D}$ simulations by Wolf and Toon 2013 at $3 \mathrm{Ga}$. Sea ice can extend toward the equator down to $37^{\circ} \mathrm{N} / \mathrm{S}$ without triggering a runaway glaciation. In the model by Charnay et al. 2013, sea ice can extend down to $25^{\circ} \mathrm{N} / \mathrm{S}$. In this model, equatorial water belts are stabilized by a cloud feedback, with a reduction of tropical low clouds due to a subsidence occurring at the ice line. Abbot et al. 2011 also found a stronger subsidence at the tropics in the case of a waterbelt state. In their model, this induces efficient evaporation of the highly reflective snow (albedo 0.8) in the tropics, leaving bare sea ice which is less reflective (albedo 0.4-0.5) and which stabilizes the waterbelt state against runaway glaciation. According to these studies, at least some surface liquid water, and thus habitable conditions, could have been maintained with only a minimal $\mathrm{CO}_{2}-\mathrm{CH}_{4}$ greenhouse. If real, such a resistance against full glaciation would mitigate the faint young Sun problem.
However, the stability of cold climates with equatorial waterbelts has been questioned by Voigt and Abbot 2012. In the case of the Neoproterozoic glaciations and using a 3D atmosphere-ocean GCM, they showed that sea-ice transport plays a major role in the triggering of full glaciation. Glaciation is initiated with 100 times more $\mathrm{CO}_{2}$ when sea-ice transport is included. We conclude that 3D GCMs with simple ocean/sea-ice models likely overestimate the stability of waterbelts. Archean cold climates with waterbelts should therefore not be considered as robust solutions to the faint young Sun problem unless their stability is demonstrated with full atmosphere-ocean GCMs.

\section{The role of biogeochemical cycles}

5.1 The carbon cycle as a key for solving the faint young Sun problem

3D climate modelling with simplified ocean/sea-ice components reveals that temperate climates with present- 

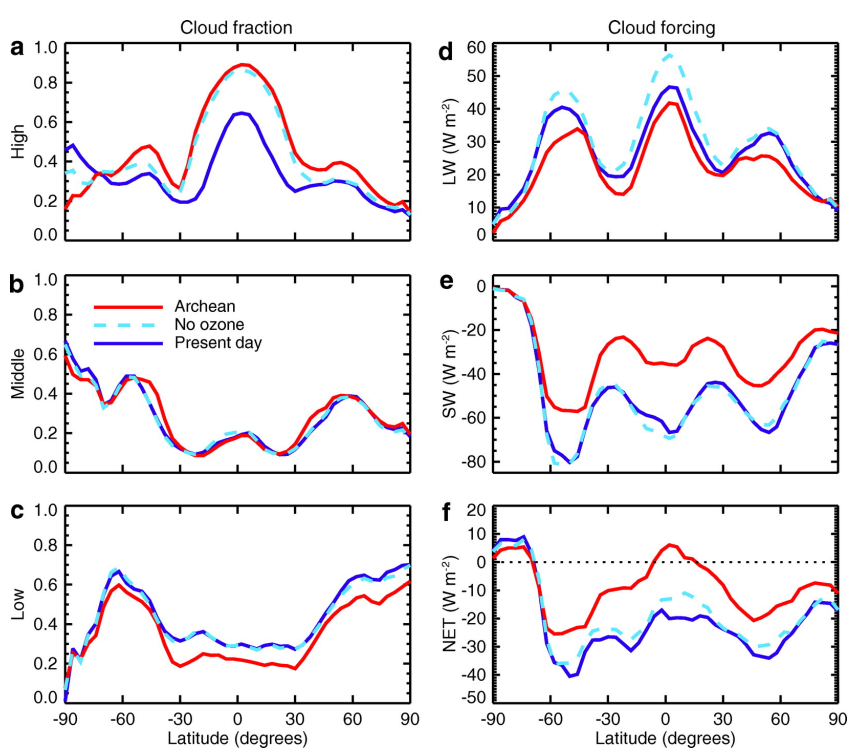

Fig. 4 Zonal mean cloud properties in 3D atmospheric simulations of the Archean (red), present day (purple), and the present-day atmosphere but with oxygen and ozone removed (dashed light blue). (a) Vertically integrated high cloud fraction. (b) Vertically integrated middle cloud fraction. (c) Vertically integrated low cloud fraction. (d) Longwave cloud forcing. (e) Shortwave cloud forcing. (f) Net cloud forcing. Figure from Wolf and Toon 2013.
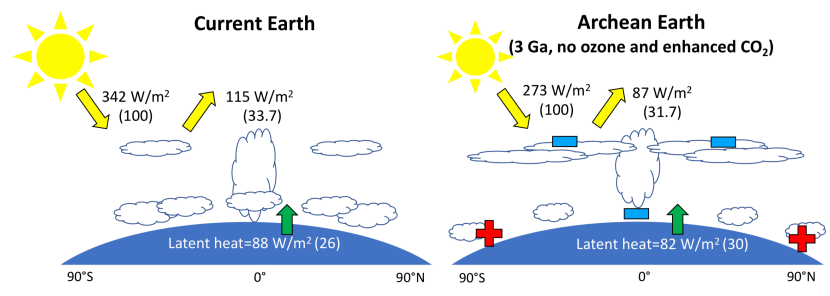

Fig. 5 Illustration of the change in cloud cover for the Archean Earth. The left panel shows the current Earth with global mean insolation at top of the atmosphere and reflected radiation (yellow arrows), latent heat flux (red arrow) and cloud cover. The fluxes in percent of the global mean insolation are given in brackets. The right panel shows the Archean Earth, with the insolation at $3 \mathrm{Ga}$, no ozone and enhanced $\mathrm{CO}_{2}$ (i.e. 60mbar) for the same global mean surface temperature as current Earth $(287.9 \mathrm{~K})$. Red + indicate the warming of high latitudes and blue - indicate the cooling of equatorial regions and the upper troposphere compared to the current Earth. The Archean Earth has less lower clouds and more upper clouds. Values are taken from Wolf and Toon 2013.

day like temperatures can be maintained for the late Archean with enhanced $\mathrm{CO}_{2}$, potentially helped by other warming processes. The carbon cycle and its ability to regulate the climate by the carbonate-silicate cycle thus appears to be a key for solving the faint young Sun problem.

Modelling of the carbon cycle of the early Earth by Sleep and Zahnle 2001] and Zahnle and Sleep 2002] suggested that the Archean was very cold unless an-

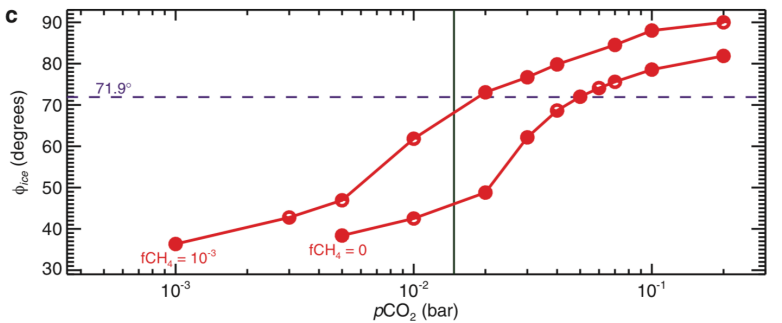

Fig. 6 Annual and hemispheric mean sea ice margin $\left(\phi_{i c e}\right)$ as a function of $\mathrm{pCO}_{2}$ from $3 \mathrm{D}$ simulations with present-day continents, the Archean Sun at $3 . \mathrm{Ga}$ and with or without methane. Purple dashed lines indicate the sea-ice extent for present-day climate. The green line indicates the $\mathrm{pCO}_{2}$ estimation by Driese et al. 2011. Figure from Wolf and Toon 2013 .

other strong greenhouse gas was present. They also suggested that the Hadean was likely fully ice-covered because of the weathering of impact ejecta, particularly during the Late Heavy Bombardment (LHB) Gomes et al., 2005, Bottke and Norman, 2017. Impact ejecta are indeed easily weathered when falling in the ocean, consuming $\mathrm{CO}_{2}$. Sleep and Zahnle 2001 and Zahnle and Sleep 2002] highlighted the importance of the seafloor weathering, caused by the reaction of seawater with the oceanic crust in low-temperature, off-axis, hydrothermal systems Brady and Gíslason, 1997, Coogan and Gillis, 2013, Coogan and Dosso, 2015. This $\mathrm{CO}_{2}$ sink would have been efficient on the early Earth with little emerged land and a high oceanic crust spreading rate. However, calculations of seafloor weathering by Sleep and Zahnle 2001 and Zahnle and Sleep 2002 did not take into account possible dependence on ocean chemistry, $\mathrm{pH}$ and oceanic temperature, and likely overestimated it. Analyses by Brady and Gíslason [1997; Coogan and Gillis 2013; Coogan and Dosso [2015 suggest that the rate of basalt dissolution and pore-space carbonate precipitation depends on bottom water temperature and/or seawater composition. In addition, reverse weathering induced by authigenic clay formation could have favoured high $\mathrm{pCO}_{2}$ on the early Earth $I s$ son and Planavsky, 2018.

More recent modelling works by Charnay et al. 2017] and Krissansen-Totton et al. [2018a], using updated climate models and parametrizations of seafloor weathering with composition/temperature dependence, revealed an efficient regulation of the carbon cycle maintaining temperate conditions for the early Earth (see Fig. 7). Seafloor weathering flux in these models is of a similar magnitude or higher than continental weathering flux. According to these studies, warm early oceans at $60^{\circ} \mathrm{C}$ can not be maintained because of the strong negative temperature feedback. Charnay et al. 2017] re- 

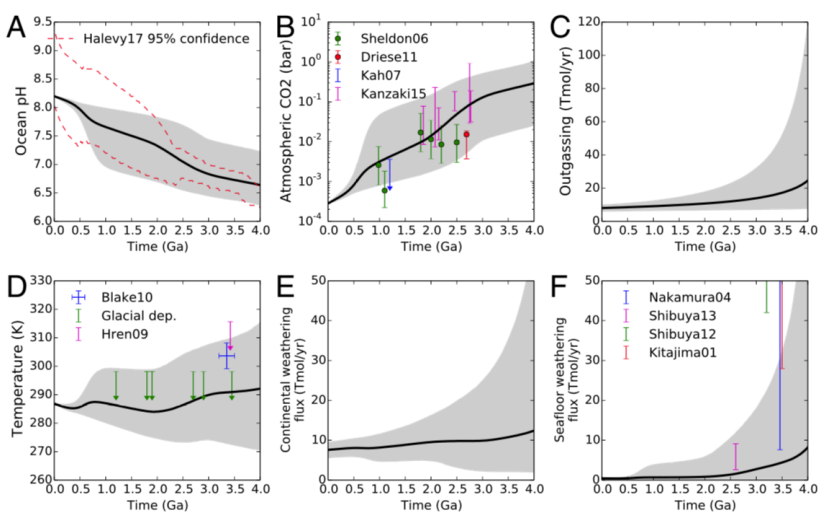

Fig. 7 Evolution of $\mathrm{pH}(\mathrm{A}), \mathrm{pCO}_{2}$ (B), global outgassing flux (C), mean surface temperature (D), continental silicate weathering flux $(\mathrm{E})$ and seafloor weathering flux $(\mathrm{F})$ over Earth's history. Gray shaded regions represent 95\% confidence intervals, and black lines are the median outputs of the carbon-cycle model from Krissansen-Totton et al. 2018a. Some geological/geochemical proxies for temperature, $\mathrm{pCO}_{2}$ and seafloor weathering are indicated. Figure from Krissansen-Totton et al. 2018a.

evaluated the long-term effect of impacts on the carbon cycle during the Late Heavy Bombardment (whose existence is still debated, see for instance Boehnke and Harrison 2016]). They found that the weathering of ejecta would have strongly decreased the partial pressure of $\mathrm{CO}_{2}$ leading to cold climates but not necessary to a snowball Earth during all that period.

In conclusion, these recent modelling studies suggest that the early Earth's climate was likely temperate, except during the Late Heavy Bombardment, and regulated by the carbon-cycle, without necessary requiring additional greenhouse gas or warming process.

\subsection{The biosphere and life feedbacks}

A fascinating topic is the role that life played in the maintenance of Earth's habitability. Some researchers have speculated that the long-term stability of Earth's climate is aided by feedbacks involving life itself Lovelock and Margulis, 1974, Schwartzman and Volk, 1989; Lenton, 1998; Lenton and von Bloh, 2001. In particular, several possible solutions to the faint young Sun problem rely on the biosphere and life feedbacks, for instance the production of $\mathrm{CH}_{4}$ by methanogens or the reduction of CCN from biological sources. In contrast, metabolic or ecological evolution could destabilize the carbon cycle or the radiative balance, inducing glacial events and mass extinctions. For instance, the Huronian glaciations, the Neoproterozoic glaciations and the
Ordovician glaciations could be related to the development of new species (i.e. cyanobacteria, algae, fungi and plants respectively) Heckman et al., 2001; Lenton et al. 2012, Feulner et al. 2015 . The C isotopic fractionation from ancient rocks suggests the presence of a productive biosphere, likely due to the early emergence of photosynthesis (oxygenic or anoxygenic) $\mathrm{Nis}$ bet and Sleep, 2001, Krissansen-Totton et al. 2015. This potentially implies a significant impact of the early biosphere on the carbon cycle, but also on the nitrogen cycle (affecting the surface pressure, see Stüeken et al. 2016) and other biogeochemical cycles (in particular sulfur and phosphorous). The question about life feedbacks is also fundamental for exoplanets, concerning the habitability and the search for biosignatures Chopra and Lineweaver, 2016. To be tested, it requires global planet models simulating the interaction between ecosystems, biogeochemical cycles and the climate.

A recent modelling work following this approach by Sauterey et al. 2020] points to the efficient methane production by primitive methanogenic ecosystems. They appear as a robust contributor to solve the faint young Sun problem. However, the methane greenhouse effect enhances rock and seafloor weathering, decreasing $\mathrm{pCO}_{2}$. At equilibrium, this negative feedbacks by the carbon cycle compensates for around $50 \%$ of the methane warming. For some conditions, the decrease of $\mathrm{pCO}_{2}$ by the carbon cycle feedback can lead to the formation of organic hazes (for $\mathrm{CH}_{4}: \mathrm{CO}_{2} \geq 0.2$ ), cooling the Earth and triggering glaciations Kanzaki and Murakami, 2018. Finally, the late appearance of methanotrophs, consuming methane once $\mathrm{pCO}_{2}$ was reduced, could also have triggered glacial events Sauterey et al. 2020]. These are examples of climate destabilization by life with primitive ecosystems. Additional work is needed to investigate all the possible implications of the early biosphere on the climate at different ages.

\section{Conclusions and perspectives}

A few years ago, the faint young Sun problem appeared to be very challenging despite the various proposed solutions: "All of these solutions present considerable difficulties, however, so the faint young Sun problem cannot be regarded as solved." Feulner, 2012. 1D atmospheric models failed to produce present-day like mean surface temperate when satisfying the geological/geochemical constraints on $\mathrm{CO}_{2}$. In addition, carbon cycle models were not able to maintain temperate climates during the Archean and the Hadean with only $\mathrm{CO}_{2}$ as greenhouse gas.

Major progress concerning the faint young Sun problem has been made during the last decade, in particu- 
lar with 3D atmospheric GCMs coupled to simplified ocean/sea-ice models which have allowed comprehensive testing of a variety of proposed solutions Charnay et al., 2013, Wolf and Toon, 2013, 2014; Le Hir et al., 2014; Kunze et al., 2014, Teitler et al., 2014; Charnay et al. , 2017. These 3D models overcame the limitations inherent to previous 1D models, taking into account fundamental climate feedbacks (clouds and seaice), atmospheric/oceanic heat transport and land distribution, although they do not capture the dynamics of sea-ice and the oceans. They suggest that a temperate early Earth is easier to achieve than previously thought. More precisely, around 200 mbar of $\mathrm{CO}_{2}$ is required at $3.8 \mathrm{Ga}$ to reach present-day mean temperate and 40 mbar at $2.5 \mathrm{Ga}$, assuming no change in Earth's continents and rotation rate. This is around half of that estimated by 1D models. This discrepancy is mostly due to cloud feedbacks with a reduction of low clouds and an increase of high clouds for enhanced $\mathrm{CO}_{2}$ and reduced insolation. Similar cloud feedbacks are predicted with 3D models used for climate future projections Boucher et al. 2013, Schneider et al. 2019]. Unfortunately, the cloud response which may have helped to warm the early Earth, may worsen the current anthropogenic climate change.

$3 \mathrm{D}$ studies also revealed that temperate climates can be reached for the late Archean with modest levels of $\mathrm{CO}_{2}$ (down to $5 \mathrm{mbar}$ ), if combined with realistic levels of $\mathrm{CH}_{4}$, reduced $\mathrm{CCN}$ and less emerged lands. $\mathrm{CH}_{4}$ appears as an excellent complement to $\mathrm{CO}_{2}$, although its warming effect saturates at $\mathrm{pCH}_{4} \sim 1$ mbar (corresponding to a warming of $\sim+14 \mathrm{~K}$ ). Ecosystem models coupled to atmospheric models suggest that $\mathrm{CH}_{4}$ concentration of the order of 0.1-1 mbar could have been reached during the Archean Ozaki et al. 2018; Sauterey et al. 2020]. The reduction of CCN appears as another robust mechanism producing optically thinner low clouds and a significant global warming (up to $\sim+10 \mathrm{~K})$. The reduction of the fraction of emerged land has a modest but non-negligeable effect (up to $\sim+4$ $\mathrm{K}$ ). All these changes (biogenic $\mathrm{CH}_{4}$, reduced $\mathrm{CCN}$ and emerged land) are plausible for the Archean Earth. In addition, recent geological constraints suggest higher levels of $\mathrm{CO}_{2}$ for the late Archean, generally $\sim 20-140$ mbar Kanzaki and Murakami, 2015 or potentially higher Lehmer et al. [2020]. Such higher values of $\mathrm{CO}_{2}$ mitigate the faint young Sun problem, since enhanced $\mathrm{CO}_{2}$ alone can then be a sufficient solution. According to recent modelling studies, these levels of $\mathrm{CO}_{2}$ could have been maintained by the carbon cycle, producing an efficient climate regulation Charnay et al., 2017, KrissansenTotton et al., 2018a. Finally, constraints of the barometric pressure and the $\mathrm{N}_{2}$ abundance suggest that the surface pressure was likely lower than today during the Archean, ruling out solutions involving a higher surface pressure and $\mathrm{N}_{2}-\mathrm{H}_{2}$ CIA.

In conclusion, the $3 \mathrm{D}$ atmospheric GCMs combined with carbon-cycle models suggest that the faint young Sun problem can be solved with higher levels of $\mathrm{CO}_{2}$, consistent with the most up to date constraints on $\mathrm{pCO}_{2}$, potentially help by additional warming processes (i.e. biological $\mathrm{CH}_{4}$, less emerged land and less CCN). The case of a temperate early Earth does not appear very problematic anymore. The case of a warm $\left(\sim 60-80^{\circ} \mathrm{C}\right)$ early Earth, which is heavily debated, remains challenging. 3D models showed that it requires less greenhouse gases than previously thought, but still exceeding most of the recent constraints on $\mathrm{CO}_{2}$ and on the barometric pressure.

Although we believe that the faint young Sun problem has essentially been solved, new geological and geochemical constraints on the atmospheric composition, pressure and surface temperature are required to get a clear picture of the early Earth's climate. Additional modelling work is also needed, in particular for quantifying the impact of ocean transport and for testing the stability of cold waterbelt states, with atmospheric GCMs fully coupled to 3D oceanic models including sea-ice transport. Such 3D atmosphere-ocean GCMs for the early Earth are a great challenge in term of modelling but would have numerous applications for past climates and for exoplanets. New simulations for low atmospheric surface pressures are also necessary to analyse the changes in terms of heat transport and cloud cover, and to estimate the $\mathrm{pCO}_{2}$ required to avoid glaciation. More generally, a major challenge is to understand the co-evolution of life and the environment on Earth. In terms of modelling, this requires to simulate the biogeochemical cycles and the couplings between the different components of the Earth system (ocean, atmosphere, biosphere, land and interior). Recent modelling studies show promising perspectives for the early Earth in this context (see for instance Stüeken et al. 2016; Krissansen-Totton et al. 2018a; Sauterey et al. 2020).

Finally, the faint young Sun problem has stimulated a lot of research and new ideas in the fields of solar physics, geology, climate science, planetary science, biology, in particular concerning the interactions between the different components of the Earth system. With its different stellar flux, rotation rate, land distribution, atmosphere and biosphere, we can view the early Earth has another habitable world or even multiple habitable worlds different from our modern Earth. The early Earth appears as a fantastic laboratory to study processes controlling the climate, the atmospheric evolu- 
tion and the habitability of exoplanets. We can dream that in return, the characterization of terrestrial exoplanets will shed light on these processes and on the environmental conditions which allowed the emergence of life on Earth.

Acknowledgements We thank the two anonymous reviewers for comments that improved the manuscript. B. Charnay acknowledges financial support from the Programme National de Planétologie (PNP) of CNRS/INSU, co-funded by CNES.

\section{References}

Abbot, D. S., A. Voigt, and D. Koll, The Jormungand global climate state and implications for Neoproterozoic glaciations, Journal of Geophysical Research (Atmospheres), 116(D18), D18103, doi:10. 1029/2011JD015927, 2011.

Abramov, O., and S. J. Mojzsis, Microbial habitability of the Hadean Earth during the late heavy bombardment, Nature, 459, 419-422, doi:10.1038/ nature08015, 2009.

Allegre, C. J., and D. Rousseau, The growth of the continent through geological time studied by Nd isotope analysis of shales, Earth and Planetary Science Letters, 67(1), 19-34, doi:10.1016/0012-821X(84) 90035-9, 1984

Arney, G., S. D. Domagal-Goldman, V. S. Meadows, E. T. Wolf, E. Schwieterman, B. Charnay, M. Claire, E. Hébrard, and M. G. Trainer, The Pale Orange Dot: The Spectrum and Habitability of Hazy Archean Earth, Astrobiology, 16(11), 873-899, doi:10.1089/ ast.2015.1422, 2016.

Asplund, M., N. Grevesse, A. J. Sauval, and P. Scott, The Chemical Composition of the Sun, Annual Review of Astronomy \& Astrophysics, 47(1), 481-522, doi:10.1146/annurev.astro.46.060407.145222, 2009.

Avice, G., B. Marty, R. Burgess, A. Hofmann, P. Philippot, K. Zahnle, and D. Zakharov, Evolution of atmospheric xenon and other noble gases inferred from Archean to Paleoproterozoic rocks, Geochimica et Cosmochimica Acta, 232, 82-100, doi:10.1016/j.gca. 2018.04.018, 2018.

Bartlett, B. C., and D. J. Stevenson, Analysis of a Precambrian resonance-stabilized day length, Geophysical Research Letters, 43(11), 5716-5724, doi: 10.1002/2016GL068912, 2016.

Belousova, E. A., Y. A. Kostitsyn, W. L. Griffin, G. C. Begg, S. Y. O'Reilly, and N. J. Pearson, The growth of the continental crust: Constraints from zircon Hf-isotope data, Lithos, 119, 457-466, doi: 10.1016/j.lithos.2010.07.024, 2010.
Benner, S. A., et al., When did life likely emerge on earth in an rna-first process?, ChemSystemsChem, 2(2), e1900,035, doi:10.1002/syst.201900035, 2020.

Blake, R. E., S. J. Chang, and A. Lepland, Phosphate oxygen isotopic evidence for a temperate and biologically active Archaean ocean, Nature, 464, 1029-1032, doi:10.1038/nature08952, 2010.

Boehnke, P., and T. M. Harrison, Illusory Late Heavy Bombardments, Proceedings of the National Academy of Science, 113, 10,802-10,806, doi:10.1073/pnas. 1611535113, 2016.

Bony, S., and J.-L. Dufresne, Marine boundary layer clouds at the heart of tropical cloud feedback uncertainties in climate models, Geophysical Research Letter, 32(20), L20806, doi:10.1029/2005GL023851, 2005.

Bony, S., et al., Clouds, circulation and climate sensitivity, Nature Geoscience, 8(4), 261-268, doi:10.1038/ ngeo2398, 2015.

Bottke, W. F., and M. D. Norman, The Late Heavy Bombardment, Annual Reviews of Earth and Planetary Sciences, 45, doi: 10.1146/annurev-earth-063016-020131, 2017.

Boucher, O., et al., Clouds and Aerosols, Climate Change 2013: The Physical Science Basis. Contribution of Working Group I to the Fifth Assessment Report of the Intergovernmental Panel on Climate Change [Stocker, T.F., D. Qin, G.-K. Plattner, M. Tignor, S.K. Allen, J. Boschung, A. Nauels, Y. Xia, V. Bex and P.M. Midgley (eds.)]. Cambridge University Press, Cambridge, United Kingdom and New York, NY, USA., 2013.

Bousseau, B., S. Blanquart, A. Necsulea, N. Lartillot, and G. Manolo, Parallel adaptations to high temperatures in the Archaean eon, Nature, 456, 942-945, doi:10.1038/nature07393, 2008.

Brady, P. V., and S. R. Gíslason, Seafloor weathering controls on atmospheric $\mathrm{CO}_{2}$ and global climate, Geochimica et Cosmochimica Acta, 61, 965-973, doi: 10.1016/S0016-7037(96)00385-7, 1997.

Budyko, M. I., The effect of solar radiation variations on the climate of the earth., Tellus, 21, 611-619, 1969.

Buldgen, G., S. Salmon, and A. Noels, Progress in global helioseismology: a new light on the solar modelling problem and its implications for solar-like stars, Frontiers in Astronomy and Space Sciences, 6, 42, doi:10.3389/fspas.2019.00042, 2019.

Byrne, B., and C. Goldblatt, Radiative forcings for 28 potential Archean greenhouse gases, Climate of the Past, 10, 1779-1801, doi:10.5194/cp-10-1779-2014, 2014.

Caffau, E., H. G. Ludwig, M. Steffen, T. R. Ayres, P. Bonifacio, R. Cayrel, B. Freytag, and B. Plez, 
The photospheric solar oxygen project. I. Abundance analysis of atomic lines and influence of atmospheric models, Astronomy and Astrophysics, 488(3), 10311046, doi:10.1051/0004-6361:200809885, 2008.

Caffau, E., H. G. Ludwig, P. Bonifacio, R. Faraggiana, M. Steffen, B. Freytag, I. Kamp, and T. R. Ayres, The solar photospheric abundance of carbon. Analysis of atomic carbon lines with the CO5BOLD solar model, Astronomy and Astrophysics, 514, A92, doi: 10.1051/0004-6361/200912227, 2010.

Cammack, J., M. Spicuzza, A. Cavosie, M. Van Kranendonk, A. Hickman, R. Kozdon, I. Orland, K. Kitajima, and J. Valley, "sims microanalysis of the strelley pool formation cherts and the implications for the secular-temporal oxygen-isotope trend of cherts", Precambrian Research, 304, 125 - 139, doi:10.1016/j. precamres.2017.11.005, 2018.

Catling, D. C., and K. J. Zahnle, The archean atmosphere, Science Advances, 6(9), doi:10.1126/sciadv. aax1420, 2020.

Charnay, B., F. Forget, R. Wordsworth, J. Leconte, E. Millour, F. Codron, and A. Spiga, Exploring the faint young Sun problem and the possible climates of the Archean Earth with a 3-D GCM, JGR, 118, 10,414, doi:10.1002/jgrd.50808, 2013.

Charnay, B., G. Le Hir, F. Fluteau, F. Forget, and D. C. Catling, A warm or a cold early Earth? New insights from a 3-D climate-carbon model, Earth and Planetary Science Letters, 474, 97-109, doi:10.1016/j.epsl. 2017.06.029, 2017.

Chopra, A., and C. H. Lineweaver, The Case for a Gaian Bottleneck: The Biology of Habitability, Astrobiology, 16(1), 7-22, doi:10.1089/ast.2015.1387, 2016.

Coogan, L. A., and S. E. Dosso, Alteration of ocean crust provides a strong temperature dependent feedback on the geological carbon cycle and is a primary driver of the Sr-isotopic composition of seawater, Earth and Planetary Science Letters, 415, 38-46, doi:10.1016/j.epsl.2015.01.027, 2015.

Coogan, L. A., and K. M. Gillis, Evidence that lowtemperature oceanic hydrothermal systems play an important role in the silicate-carbonate weathering cycle and long-term climate regulation, Geochemistry, Geophysics, Geosystems, 14, 1771-1786, doi: 10.1002/ggge.20113, 2013.

de Wit, M. J., and H. Furnes, 3.5-Ga hydrothermal fields and diamictites in the Barberton Greenstone Belt-Paleoarchean crust in cold environments, Science Advances, 2(2), e1500,368-e1500,368, doi:10. 1126/sciadv.1500368, 2016.

Dhuime, B., C. J. Hawkesworth, P. A. Cawood, and C. D. Storey, A Change in the Geodynamics of Continental Growth 3 Billion Years Ago, Science,
335 (6074), 1334, doi:10.1126/science.1216066, 2012.

Driese, S., M. Jirsa, M. Ren, S. Brantley, N. Sheldon, D. Parker, and M. Schmitz, Neoarchean paleoweathering of tonalite and metabasalt: Implications for reconstructions of 2.69 ga early terrestrial ecosystems and paleoatmospheric chemistry, Precambrian Research, 189, 1-17, doi:10.1016/j.precamres. 2011.04.003, 2011.

Feulner, G., The faint young Sun problem, Reviews of Geophysics, 50, RG2006, doi:10.1029/ 2011RG000375, 2012.

Feulner, G., C. Hallmann, and H. Kienert, Snowball cooling after algal rise, Nature Geoscience, 8(9), 659662, doi:10.1038/ngeo2523, 2015.

Fichtinger, B., M. Güdel, R. L. Mutel, G. Hallinan, E. Gaidos, S. L. Skinner, C. Lynch, and K. G. Gayley, Radio emission and mass loss rate limits of four young solar-type stars, Astronomy \& Astrophysics, 599, A127, doi:10.1051/0004-6361/201629886, 2017.

Flament, N., N. Coltice, and P. F. Rey, A case for late-Archaean continental emergence from thermal evolution models and hypsometry, Earth and Planetary Science Letters, 275, 326-336, doi:10.1016/j. epsl.2008.08.029, 2008.

Flato, G., et al., Evaluation of Climate Models., Climate Change 2013: The Physical Science Basis. Contribution of Working Group I to the Fifth Assessment Report of the Intergovernmental Panel on Climate Change [Stocker, T.F., D. Qin, G.-K. Plattner, M. Tignor, S.K. Allen, J. Boschung, A. Nauels, Y. Xia, V. Bex and P.M. Midgley (eds.)]. Cambridge University Press, Cambridge, United Kingdom and New York, NY, USA., 2013.

Forget, F., R. Wordsworth, E. Millour, J. B. Madeleine, L. Kerber, J. Leconte, E. Marcq, and R. M. Haberle, $3 \mathrm{D}$ modelling of the early martian climate under a denser $\mathrm{CO}_{2}$ atmosphere: Temperatures and $\mathrm{CO}_{2}$ ice clouds, Icarus, 222(1), 81-99, doi:10.1016/j.icarus. 2012.10.019, 2013.

Foriel, J., P. Philippot, P. Rey, A. Somogyi, D. Banks, and $\mathrm{B}$. Ménez, Biological control of $\mathrm{Cl} / \mathrm{Br}$ and low sulfate concentration in a 3.5-Gyr-old seawater from North Pole, Western Australia, Earth and Planetary Science Letters, 228(3-4), 451-463, doi:10.1016/ j.epsl.2004.09.034, 2004.

Fralick, P., and J. Carter, Neoarchean deep marine paleotemperature: Evidence from turbidite successions, Precambrian Research, 191, 78-84, doi:10.1016/j. precamres.2011.09.004, 2011.

Gaillard, F., and B. Scaillet, A theoretical framework for volcanic degassing chemistry in a comparative planetology perspective and implications for planetary atmospheres, Earth and Planetary Science 
Letters, 403, 307-316, doi:10.1016/j.epsl.2014.07.009, 2014.

Gallet, F., and J. Bouvier, Improved angular momentum evolution model for solar-like stars, Astronomy and Astrophysics, 556, A36, doi:10.1051/0004-6361/ 201321302, 2013.

Gaucher, E. A., S. Govindarajan, and O. K. Ganesh, Palaeotemperature trend for Precambrian life inferred from resurrected proteins, Nature, 452, 704707, doi:10.1038/nature06510, 2008.

Genda, H., and Y. Abe, Enhanced atmospheric loss on protoplanets at the giant impact phase in the presence of oceans, Nature, 433(7028), 842-844, doi: 10.1038/nature03360, 2005.

Goldblatt, C., and K. J. Zahnle, Clouds and the Faint Young Sun Parados, Climate of the Past, 7, 203-220, doi:10.5194/cp-7-203-2011, 2011a.

Goldblatt, C., and K. J. Zahnle, Faint young Sun paradox remains, Nature, 474, doi:10.1038/nature09961, 2011b.

Goldblatt, C., T. M. Lenton, and A. J. Watson, Bistability of atmospheric oxygen and the Great Oxidation, Nature, 443(7112), 683-686, doi:10.1038/ nature05169, 2006.

Goldblatt, C., M. W. Claire, T. M. Lenton, A. J. Matthews, and A. J. Watson, Nitrogen-enhanced greenhouse warming on early Earth, Nature Geoscience, 2, 891-896, 2009.

Gomes, R., H. F. Levison, K. Tsiganis, and A. Morbidelli, Origin of the cataclysmic Late Heavy Bombardment period of the terrestrial planets, Nature, 435, 466-469, doi:10.1038/nature03676, 2005.

Goosmann, E. A., D. C. Catling, S. M. Som, W. Altermann, and R. Buick, Eolianite Grain Size Distributions as a Proxy for Large Changes in Planetary Atmospheric Density, Journal of Geophysical Research (Planets), 123(10), 2506-2526, doi:10.1029/ 2018JE005723, 2018.

Gough, D., Solar interior structure and luminosity variations, Solar Physics, 74, 21-34, doi:10.1007/ BF00151270, 1981

Guzik, J. A., and K. Mussack, Exploring Mass Loss, Low-Z Accretion, and Convective Overshoot in Solar Models to Mitigate the Solar Abundance Problem, Astrophys. J., 713(2), 1108-1119, doi:10.1088/ 0004-637X/713/2/1108, 2010.

Guzmán-Marmolejo, A., A. Segura, and E. EscobarBriones, Abiotic Production of Methane in Terrestrial Planets full access, Astrobiology, 13(6), 550-559, doi:10.1089/ast.2012.0817, 2013.

Haberle, R. M., D. C. Catling, M. H. Carr, and K. J. Zahnle, The Early Mars Climate System, pp. 497525, doi:10.1017/9781139060172.017, 2017.
Haqq-Misra, J. D., S. D. Domagal-Goldman, P. J. Kasting, and J. F. Kasting, A Revised, Hazy Methane Greenhouse for the Archean Earth, Astrobiology, 8, 1127-1137, doi:10.1089/ast.2007.0197, 2008.

Hawkesworth, C., P. Cawood, and B. Dhuime, Rates of generation and growth of the continental crust, Geoscience Frontiers, 10(1), 165 - 173, doi:https:// doi.org/10.1016/j.gsf.2018.02.004, 2019.

Heckman, D. S., D. M. Geiser, B. R. Eidell, R. L. Stauffer, N. L. Kardos, and S. B. Hedges, Molecular evidence for the early colonization of land by fungi and plants, Science, 293(5532), 1129-1133, doi: 10.1126/science.1061457, 2001.

Hoffman, P. F., et al., Snowball Earth climate dynamics and Cryogenian geology-geobiology, Science Advances, 3(11), e1600,983, doi:10.1126/sciadv. $1600983,2017$.

Hren, M. T., M. M. Tice, and C. P. Chamberlain, Oxygen and hydrogen isotope evidence for a temperate climate 3.42 billion years ago, Nature, 462, 205-208, doi:10.1038/nature08518, 2009.

Isson, T. T., and N. J. Planavsky, Reverse weathering as a long-term stabilizer of marine $\mathrm{pH}$ and planetary climate, Nature, 560(7719), 471-475, doi: 10.1038/s41586-018-0408-4, 2018.

Jaffrés, J. B. D., G. A. Shields, and K. Wallmann, The oxygen isotope evolution of seawater: A critical review of a long-standing controversy and an improved geological water cycle model for the past 3.4 billion years, Earth Science Reviews, 83, 83-122, doi: 10.1016/j.earscirev.2007.04.002, 2007.

Jenkins, G. S., and S. R. Smith, GCM simulations of snowball earth conditions during the Late Proterozoic, Geophysical Research Letters, 26(15), 22632266, doi:10.1029/1999GL900538, 1999.

Jenkins, G. S., H. G. Marshall, and W. R. Kuhn, Precambrian climate: The effects of land area and Earth's rotation rate, Journal of Geophysical Research, 98, 8785-8791, 1993.

Kadoya, S., and D. C. Catling, Constraints on hydrogen levels in the Archean atmosphere based on detrital magnetite, Geochimica et Cosmochimica Acta, 262, 207-219, doi:10.1016/j.gca.2019.07.041, 2019.

Kanzaki, Y., and T. Murakami, Estimates of atmospheric $\mathrm{CO}_{2}$ in the Neoarchean-Paleoproterozoic from paleosols, Geochimica et Cosmochimica Acta, 159, 190-219, doi:10.1016/j.gca.2015.03.011, 2015.

Kanzaki, Y., and T. Murakami, Effects of atmospheric composition on apparent activation energy of silicate weathering: II. Implications for evolution of atmospheric $\mathrm{CO}_{2}$ in the Precambrian, Geochimica et Cosmochimica Acta, 240, 314-330, doi:10.1016/j.gca. 2018.08.020, 2018. 
Kasting, J. F., Stability of ammonia in the primitive terrestrial atmosphere, Journal of Geophysical Research, 87(C4), 3091-3098, doi:10.1029/ JC087iC04p03091, 1982.

Kasting, J. F., and T. M. Howard, Atmospheric composition and climate on the early Earth, Phil. Trans. R. Soc., 361, 1733-1742, doi:10.1098/rstb.2006.1902, 2006.

Kasting, J. F., and S. Ono, Palaeoclimates: the first two billion years, Phil. Trans. R. Soc., 361, 917-929, doi: 10.1098/rstb.2006.1839, 2006.

Kasting, J. F., J. B. Pollack, and D. Crisp, Effects of high CO2 levels on surface temperature and atmospheric oxidation state of the early earth, Journal of Atmospheric Chemistry, 1, 403-428, 1984.

Kasting, J. F., M. T. Howard, K. Wallmann, J. Veizer, G. Shields, and J. Jaffres, Paleoclimates, ocean depth, and the oxygen isotopic composition of seawater, Earth and Planetary Science Letters, 252, 82-93, doi:10.1016/j.epsl.2006.09.029, 2006.

Kavanagh, L., and C. Goldblatt, Using raindrops to constrain past atmospheric density, Earth and Planetary Science Letters, 413, 51-58, doi:10.1016/j.epsl. 2014.12.032, 2015.

Kharecha, P., J. Kasting, and J. Siefert, A coupled atmosphere-ecosystem model of the early archean earth, Geobiology, 3(2), 53-76, doi:10.1111/ j.1472-4669.2005.00049.x, 2005.

Kiehl, J. T., and R. E. Dickinson, A study of the radiative effects of enhanced atmospheric $\mathrm{CO}_{2}$ and $\mathrm{CH}_{4}$ on early Earth surface temperatures, Journal of Geophysical ResearchJournal of Geophysical Research, 92, 2991-2998, doi:10.1029/JD092iD03p02991, 1987.

Kienert, H., G. Feulner, and V. Petoukhov, Faint young Sun problem more severe due to ice-albedo feedback and higher rotation rate of the early Earth, Geophysical Research Letters, 39(23), L23710, doi: 10.1029/2012GL054381, 2012.

Knauth, L. P., and D. R. Lowe, High Archean climatic temperature inferred from oxygen isotope geochemistry of cherts in the 3.5 Ga Swaziland Supergroup, South Africa, Geological Society of America Bulletin, 115, 566-580, doi:10.1130/0016-7606(2003)115<0566: HACTIF $>2.0 . \mathrm{CO} ; 2,2003$.

Krissansen-Totton, J., and D. C. Catling, Constraining climate sensitivity and continental versus seafloor weathering using an inverse geological carbon cycle model, Nature Communications, 8, 15423, doi: 10.1038/ncomms15423, 2017.

Krissansen-Totton, J., R. Buick, and D. C. Catling, A statistical analysis of the carbon isotope record from the Archean to Phanerozoic and implications for the rise of oxygen, American Journal of Science, 315(4),
275-316, doi:10.2475/04.2015.01, 2015.

Krissansen-Totton, J., G. N. Arney, and D. C. Catling, Constraining the climate and ocean $\mathrm{pH}$ of the early Earth with a geological carbon cycle model, Proceedings of the National Academy of Science, 115(16), 4105-4110, doi:10.1073/pnas.1721296115, 2018a.

Krissansen-Totton, J., S. Olson, and D. C. Catling, Disequilibrium biosignatures over Earth history and implications for detecting exoplanet life, Science Advances, 4(1), eaao5747, doi:10.1126/sciadv.aao5747, 2018 b.

Kunze, M., M. Godolt, U. Langematz, J. L. Grenfell, A. Hamann-Reinus, and H. Rauer, Investigating the early Earth faint young Sun problem with a general circulation model, Planetary and Space Science, 98, 77-92, doi:10.1016/j.pss.2013.09.011, 2014.

Kuramoto, K., T. Umemoto, and M. Ishiwatari, Effective hydrodynamic hydrogen escape from an early Earth atmosphere inferred from high-accuracy numerical simulation, Earth and Planetary Science Letters, 375, 312-318, doi:10.1016/j.epsl.2013.05.050, 2013.

Le Hir, G., Y. Teitler, F. Fluteau, Y. Donnadieu, and P. Philippot, The faint young Sun problem revisited with a $3-\mathrm{D}$ climate-carbon model - Part 1, Climate of the Past, 10, 697-713, doi:10.5194/cp-10-697-2014, 2014.

Lehmer, O. R., D. C. Catling, R. Buick, D. E. Brownlee, and S. Newport, Atmospheric CO2 levels from 2.7 billion years ago inferred from micrometeorite oxidation, Science Advances, 6(4), eaay4644, doi: 10.1126/sciadv.aay4644, 2020.

Lenton, T. M., Gaia and natural selection, Nature, 394(6692), 439-447, doi:10.1038/28792, 1998.

Lenton, T. M., and W. von Bloh, Biotic feedback extends the life span of the biosphere, Geophysical research Letters, 28(9), 1715-1718, doi:10.1029/ 2000GL012198, 2001.

Lenton, T. M., M. Crouch, M. Johnson, N. Pires, and L. Dolan, First plants cooled the Ordovician, Nature Geoscience, 5(2), 86-89, doi:10.1038/ngeo1390, 2012.

Lindzen, R. S., M.-D. Chou, and A. Y. Hou, Does the Earth Have an Adaptive Infrared Iris?., Bulletin of the American Meteorological Society, 82, 417-432, doi:10.1175/1520-0477(2001)082〈0417: DTEHAA $>2.3 . \mathrm{CO} ; 2,2001$.

Lovelock, J. E., and L. Margulis, Atmospheric homeostasis by and for the biosphere: The gaia hypothesis, Tellus, 26, 2, 1974.

Lyons, T. W., C. T. Reinhard, and N. J. Planavsky, The rise of oxygen in Earth's early ocean and atmosphere, Nature, 506, 307-315, doi:10.1038/ nature13068, 2014. 
Marin-Carbonne, J., M. Chaussidon, and F. Robert, Micrometer-scale chemical and isotopic criteria (O and $\mathrm{Si}$ ) on the origin and history of Precambrian cherts: Implications for paleo-temperature reconstructions, Geochimica et Cosmochimica Acta, 92, 129-147, doi:10.1016/j.gca.2012.05.040, 2012.

Marin-Carbonne, J., M. Chaussidon, and F. Robert, The silicon and oxygen isotope compositions of Precambrian cherts: A record of oceanic paleotemperatures?, Precambrian Research, 247, 223-234, doi:10.1016/j.precamres.2014.03.016, 2014.

Martens, P. C., The Faint Young Sun and Faint Young Stars Paradox, in Living Around Active Stars, IAU Symposium, vol. 328, edited by D. Nandy, A. Valio, and P. Petit, pp. 350-355, doi:10.1017/ S1743921317004331, 2017.

Marty, B., L. Zimmermann, M. Pujol, R. Burgess, and P. Philippot, Nitrogen isotopic composition and density of the archean atmosphere, Science, 342(6154), 101-104, doi:10.1126/science.1240971, 2013.

Marty, B., G. Avice, D. V. Bekaert, and M. W. Broadley, Salinity of the Archaean oceans from analysis of fluid inclusions in quartz, Comptes Rendus Geoscience, 350(4), 154-163, doi:10.1016/j.crte. 2017.12.002, 2018.

Mauritsen, T., and B. Stevens, Missing iris effect as a possible cause of muted hydrological change and high climate sensitivity in models, Nature Geoscience, 8(5), 346-351, doi:10.1038/ngeo2414, 2015.

McKay, C. P., J. B. Pollack, and R. Courtin, The greenhouse and antigreenhouse effects on Titan, Science, 253, 1118-1121, doi:10.1126/science.253.5024.1118, 1991.

Minton, D. A., and R. Malhotra, Assessing the Massive Young Sun Hypothesis to Solve the Warm Young Earth Puzzle, Astrophys. J., 660(2), 1700-1706, doi: 10.1086/514331, 2007.

Mojzsis, S. J., T. M. Harrison, and R. T. Pidgeon, Oxygen-isotope evidence from ancient zircons for liquid water at the Earth's surface $4,300 \mathrm{Myr}$ ago, $\mathrm{Na}$ ture, 409(6817), 178-181, 2001.

Newman, M. J., and R. T. Rood, Implications of Solar Evolution for the Earth's Early Atmosphere, Science, 198(4321), 1035-1037, doi:10.1126/science.198.4321. 1035, 1977.

Nisbet, E. G., and N. H. Sleep, The habitat and nature of early life, Nature, 409, 1083-1091, 2001.

Ojakangas, R., V. S. Srinivasan, R. and Hegde, S. M. Chandrakant, and S. V. Srikantia, The talya conglomerate: an archean $(\sim 2.7$ ga) glaciomarine formation, western dharwar craton, southern india, Current Science, 106(3), 387-396, 2014.
Owen, T., R. D. Cess, and V. Ramanathan, Enhanced $\mathrm{CO}_{2}$ greenhouse to compensate for reduced solar luminosity on early Earth, Nature, 277, 640-642, doi: 10.1038/277640a0, 1979.

Ozaki, K., E. Tajika, P. K. Hong, Y. Nakagawa, and C. T. Reinhard, Effects of primitive photosynthesis on Earth's early climate system, Nature Geoscience, 11 (1), 55-59, doi:10.1038/s41561-017-0031-2, 2018.

Pavlov, A. A., J. F. Kasting, L. L. Brown, K. A. Rages, and R. Freedman, Greenhouse warming by $\mathrm{CH}_{4}$ in the atmosphere of early Earth, Journal of Geophysical Research, 105, 11,981-11,990, doi:10.1029/ 1999JE001134, 2000.

Pavlov, A. A., L. L. Brown, and J. F. Kasting, UV shielding of $\mathrm{NH}_{3}$ and $\mathrm{O}_{2}$ by organic hazes in the Archean atmosphere, Journal of Geophysical Research, 106, 23,267-23,287, doi:10.1029/ 2000JE001448, 2001.

Pierrehumbert, R. T., Thermostats, Radiator Fins, and the Local Runaway Greenhouse, Journal of the Atmospheric Sciences, 52, 1784-1806, 1995.

Pierrehumbert, R. T., High levels of atmospheric carbon dioxide necessary for the termination of global glaciation, Nature, 429(6992), 646-649, doi:10.1038/ nature02640, 2004.

Pope, E. C., D. K. Bird, and M. T. Rosing, Isotope composition and volume of Earth's early oceans, Proceedings of the National Academy of Sciences, 109(12), 4371-4376, doi:10.1073/pnas.1115705109, 2012.

Pujol, M., B. Marty, R. Burgess, G. Turner, and P. Philippot, Argon isotopic composition of Archaean atmosphere probes early Earth geodynamics, Nature, 498(7452), 87-90, doi:10.1038/nature12152, 2013.

Reinhard, C., and N. Planavsky, Mineralogical constraints on Precambrian pCO2, Nature, doi:doi:10. 1038/nature09959, 2011.

Rey, P. F., and N. Coltice, Neoarchean lithospheric strengthening and the coupling of Earth's geochemical reservoirs, Geology, 36(8), 635-638, doi:10.1130/ G25031A.1, 2008.

Robert, F., and M. Chaussidon, A palaeotemperature curve for the Precambrian oceans based on silicon isotopes in cherts, Nature, 443, 969-972, 2006.

Rondanelli, R., and R. S. Lindzen, Can thin cirrus clouds in the tropics provide a solution to the faint young Sun paradox?, Journal of Geophysical Research (Atmospheres), 115, D02108, doi:10.1029/ 2009JD012050, 2010.

Rosing, M. T., D. K. Bird, N. H. Sleep, and C. J. Bjerrum, No climate paradox under the faint early Sun, Nature, 464 (7289), 744-747, 2010.

Rye, R., P. H. Kuo, and H. D. Holland, Atmospheric carbon dioxide concentrations before 2.2 billion years 
ago, Nature, 378, 603-605, doi:10.1038/378603a0, 1995.

Sagan, C., and G. Mullen, Earth and Mars: Evolution of Atmospheres and Surface Temperatures, Science, 177, 52-56, doi:10.1126/science.177.4043.52, 1972.

Sauterey, B., B. Charnay, A. Affholder, S. Mazevet, and R. Ferriére, Co-evolution of primitive methanecycling ecosystems and early Earth's atmosphere and climate, Nature Communications, 11 (2705), doi: https://doi.org/10.1038/s41467-020-16374-7, 2020.

Schneider, T., C. M. Kaul, and K. G. Pressel, Possible climate transitions from breakup of stratocumulus decks under greenhouse warming, Nature Geoscience, 12(3), 163-167, doi:10.1038/ s41561-019-0310-1, 2019.

Schwartzman, D. W., and T. Volk, Biotic enhancement of weathering and the habitability of Earth, Nature, 340 (6233), 457-460, doi:10.1038/340457a0, 1989.

Schwieterman, E. W., C. T. Reinhard, S. L. Olson, K. Ozaki, C. E. Harman, P. K. Hong, and T. W. Lyons, Rethinking CO Antibiosignatures in the Search for Life Beyond the Solar System, Astrophys. J., 874(1), 9, doi:10.3847/1538-4357/ab05e1, 2019.

Sellers, W. D., A Global Climatic Model Based on the Energy Balance of the Earth-Atmosphere System., Journal of Applied Meteorology, 8(3), 392-400, doi:10.1175/1520-0450(1969)008<0392: AGCMBO $\rangle$ 2.0.CO;2, 1969.

Sengupta, S., and A. Pack, Triple oxygen isotope mass balance for the Earth's oceans with application to Archean cherts, Chemical Geology, 495, 18-26, doi: 10.1016/j.chemgeo.2018.07.012, 2018.

Sheldon, N., Precambrian paleosols and atmospheric CO2 levels, Precambrian Research, 147, 148-155, doi: 10.1016/j.precamres.2006.02.004, 2006.

Sleep, N. H., and K. Zahnle, Carbon dioxide cycling and implications for climate on ancient Earth, Journal of Geophysical Research, 106, 1373-1400, doi:10.1029/ 2000JE001247, 2001.

Sleep, N. H., K. Zahnle, and P. S. Neuhoff, Inaugural Article: Initiation of clement surface conditions on the earliest Earth, Proceedings of the $\mathrm{Na}$ tional Academy of Science, 98(7), 3666-3672, doi: 10.1073/pnas.071045698, 2001.

Som, S. M., D. C. Catling, J. P. Harnmeijer, P. M. Polivka, and R. Buick, Air density 2.7 billion years ago limited to less than twice modern levels by fossil raindrop imprints., Nature, 484 (7394), 359-362, doi: 10.1038/nature10890, 2012.

Som, S. M., R. Buick, J. W. Hagadorn, T. S. Blake, J. M. Perreault, J. P. Harnmeijer, and D. C. Catling, Earth's air pressure 2.7 billion years ago constrained to less than half of modern levels, Nature Geoscience, 9, 448-451, doi:10.1038/ngeo2713, 2016.

Spalding, C., W. W. Fischer, and G. Laughlin, An Orbital Window into the Ancient Sun's Mass, Astrophys. J. L., 869(1), L19, doi:10.3847/2041-8213/ aaf219, 2018.

Stüeken, E. E., R. Buick, B. M. Guy, and M. C. Koehler, Isotopic evidence for biological nitrogen fixation by molybdenum-nitrogenase from 3.2 Gyr, $\mathrm{Na}$ ture, 520(7549), 666-669, doi:10.1038/nature14180, 2015 .

Stüeken, E. E., M. A. Kipp, M. C. Koehler, E. W. Schwieterman, B. Johnson, and R. Buick, Modeling $\mathrm{pN}_{2}$ through Geological Time: Implications for Planetary Climates and Atmospheric Biosignatures, Astrobiology, 16(12), 949-963, doi:10.1089/ast.2016. 1537, 2016.

Tartese, R., C. M., A. Gurenko, F. Delarue, and F. Robert, Warm Archean oceans reconstructed from oxygen isotope composition of early-life remnants, Geochemical Perspective letters, 3, 55-65, doi:10. 1126/science.aad5513, 2016.

Teitler, Y., G. Ler Hir, F. Fluteau, P. Philippot, and Y. Donnadieu, Investigating the paleoproterozoic glaciations with 3-d climate modeling, Earth and Planetary Science Letters, 395, 71 - 80, doi: https://doi.org/10.1016/j.epsl.2014.03.044, 2014.

Tian, F., O. B. Toon, A. A. Pavlov, and H. De Sterck, A Hydrogen-Rich Early Earth Atmosphere, Science, 308, 1014-1017, doi:10.1126/science.1106983, 2005.

Tian, F., J. F. Kasting, and K. Zahnle, Revisiting HCN formation in Earth's early atmosphere, Earth and Planetary Science Letters, 308, 417-423, doi: 10.1016/j.epsl.2011.06.011, 2011.

Trainer, M. G., A. A. Pavlov, H. L. Dewitt, J. L. Jimenez, C. P. McKay, O. B. Toon, and M. A. Tolbert, Inaugural Article: Organic haze on Titan and the early Earth, PNAS, 103, 18,035-18,042, doi: 10.1073/pnas.0608561103, 2006.

Turck-Chièze, S., L. Piau, and S. Couvidat, The Solar Energetic Balance Revisited by Young Solar Analogs, Helioseismology, and Neutrinos, Astrophys. J. L., 731 (2), L29, doi:10.1088/2041-8205/731/2/ L29, 2011.

Urata, R. A., and O. B. Toon, Simulations of the martian hydrologic cycle with a general circulation model: Implications for the ancient martian climate, Icarus, 226, 229-250, doi:10.1016/j.icarus.2013.05. 014, 2013.

van den Boorn, S., M. van Bergen, W. Nijman, and P. Vroon, Dual role of seawater and hydrothermal fluids in Early Archean chert formation: Evidence from silicon isotopes, Geology, 35, 939, doi:10.1130\$〉 
$\% \$ 2 F G 24096$ A.1, 2007.

Voigt, A., and D. S. Abbot, Sea-ice dynamics strongly promote Snowball Earth initiation and destabilize tropical sea-ice margins, Climate of the Past, 8(6), 2079-2092, doi:10.5194/cp-8-2079-2012, 2012.

von Paris, P., H. Rauer, J. Lee Grenfell, B. Patzer, P. Hedelt, B. Stracke, T. Trautmann, and F. Schreier, Warming the early earth- $\mathrm{CO}_{2}$ reconsidered, Planetary and Space Science, 56, 1244-1259, doi:10.1016/ j.pss.2008.04.008, 2008.

Walker, J. C. G., P. B. Hays, and J. F. Kasting, A negative feedback mechanism for the long-term stabilization of the earth's surface temperature, Journal of Geophysical Research, 86, 9776-9782, doi:10.1029/ JC086iC10p09776, 1981.

Whitmire, D. P., L. R. Doyle, R. T. Reynolds, and J. J. Matese, A slightly more massive young Sun as an explanation for warm temperatures on early Mars, Journal of Geophysical Research, 100(E3), 54575464, doi:10.1029/94JE03080, 1995.

Wild, M., D. Folini, C. Schär, N. Loeb, E. G. Dutton, and G. König-Langlo, The global energy balance from a surface perspective, Climate Dynamics, 40(11-12), 3107-3134, doi:10.1007/ s00382-012-1569-8, 2013.

Wilde, S. A., J. W. Valley, W. H. Peck, and C. M. Graham, Evidence from detrital zircons for the existence of continental crust and oceans on the Earth 4.4Gyr ago, Nature, 409(6817), 175-178, 2001.

Williams, G. E., Geological constraints on the Precambrian history of Earth's rotation and the Moon's orbit, Reviews of Geophysics, 38, 37-60, doi:10.1029/ 1999RG900016, 2000.

Wolf, E. T., and O. B. Toon, Fractal Organic Hazes Provided an Ultraviolet Shield for Early Earth, Science, 328(5983), 1266-1268, doi:10.1126/science.1183260, 2010.

Wolf, E. T., and O. B. Toon, Hospitable Archean Climates Simulated by a General Circulation Model, Astrobiology, 13, 656-673, doi:10.1089/ast.2012.0936, 2013.

Wolf, E. T., and O. B. Toon, Controls on the Archean Climate System Investigated with a Global Climate Model, Astrobiology, 14, 241-253, doi:10.1089/ast. 2013.1112, 2014.

Wolf, E. T., J. Haqq-Misra, and O. B. Toon, Evaluating Climate Sensitivity to $\mathrm{CO}_{2}$ Across Earth's History, Journal of Geophysical Research (Atmospheres), 123(21), 11,861-11,874, doi:10.1029/2018JD029262, 2018.

Wood, B. E., H.-R. Müller, G. P. Zank, and J. L. Linsky, Measured Mass-Loss Rates of Solar-like Stars as a Function of Age and Activity, Astrophysical Jour- nal, 574(1), 412-425, doi:10.1086/340797, 2002.

Wood, B. E., H. R. Müller, G. P. Zank, J. L. Linsky, and S. Redfield, New Mass-Loss Measurements from Astrospheric Ly $\alpha$ Absorption, Astrophys. J. L., 628(2), L143-L146, doi:10.1086/432716, 2005.

Wood, S. R., K. Mussack, and J. A. Guzik, Solar Models with Dynamic Screening and Early Mass Loss Tested by Helioseismic, Astrophysical, and Planetary Constraints, Solar Physics, 293(7), 111, doi: 10.1007/s11207-018-1334-1, 2018.

Wordsworth, R., and R. Pierrehumbert, HydrogenNitrogen Greenhouse Warming in Earth's Early Atmosphere, Science, 339(6115), 64, doi:10.1126/ science.1225759, 2013.

Zahnle, K., and N. H. Sleep, Carbon dioxide cycling through the mantle and implications for the climate of ancient Earth, Geological Society of London Special Publications, 199, 231-257, doi:10.1144/GSL.SP. 2002.199.01.12, 2002.

Zahnle, K., and J. C. G. Walker, A constant daylength during the precambrian era?, Precambrian Research, 37, 95-105, 1987.

Zahnle, K. J., Photochemistry of methane and the formation of hydrocyanic acid (HCN)in the earth's early atmosphere, Journal of Geophysical Research, 91, 2819-2834, doi:10.1029/JD091iD02p02819, 1986.

Zahnle, K. J., M. Gacesa, and D. C. Catling, Strange messenger: A new history of hydrogen on Earth, as told by Xenon, Geochimica et Cosmochimica Acta, 244, 56-85, doi:10.1016/j.gca.2018.09.017, 2019.

Zank, G. P., Interaction of the solar wind with the local interstellar medium: a theoretical perspective, Space Science reviews, 89, 413-688, doi:10.1023/A: $1005155601277,1999$.

Zelinka, M. D., S. A. Klein, K. E. Taylor, T. Andrews, M. J. Webb, J. M. Gregory, and P. M. Forster, Contributions of Different Cloud Types to Feedbacks and Rapid Adjustments in CMIP5*, Journal of Climate, 26 (14), 5007-5027, doi:10.1175/JCLI-D-12-00555.1, 2013.

Zerkle, A. L., M. W. Claire, S. D. Domagal-Goldman, J. Farquhar, and S. W. Poulton, A bistable organicrich atmosphere on the Neoarchaean Earth, Nature Geoscience, 5, 359-363, doi:10.1038/ngeo1425, 2012. 